\title{
Subject-indexing and possessive morphology in Northwest Solomonic
}

\author{
BILL PALMER
}

\section{Abstract}

Most Northwest Solomonic (NWS) languages employ possessor-indexing or former possessor-indexing morphology to index subject on verbs. Although the phenomenon of dependent-marking languages using cognate morphology to case mark possessors and subjects is well known, head marking in the form of subject agreement using possessor-indexing morphology of the kind seen in NWS is less well understood. Moreover, most instances of cognate possessorindexing and subject-indexing morphology typically result from independent pronouns in parallel processes of grammaticalization. In NWS the subjectindexing function arose from a well-established preexisting possessor-indexing function, demonstrating a diachronic functional shift from nominal marking to verb marking. Moreover, in several NWS languages two possessor-indexing hosts encoding distinct semantic categories of possession occur in verbal constructions marking different kinds of events, raising the question of how a semantic distinction between kinds of entities can be meaningfully applied to categories of events.

This article surveys functional and formal characteristics of synchronic "possessive" subject-indexing morphology across NWS, and proposes an originating nominalization construction in Proto-NWS from which the synchronic phenomena arose. It reappraises Ross's (1982) hypothesis on the origin of the phenomenon, and the hypothesis that two distinct clause structures are involved in the presence or absence of this morphology. It then investigates several key problems not previously addressed, including why the order of subject-indexing morphology and verb it accompanies is the reverse of the order of possessor-indexing morphology and noun in nominal constructions, and how distinct nominal categories of possession encoded by the two possessor-indexing hosts could be reinterpreted as a verbal distinction of event type. 


\section{Introduction ${ }^{1}$}

In every subgroup of the Northwest Solomonic (NWS) branch of Oceanic, morphology also or formerly used with a nominal possessor-indexing function occurs in verbal constructions indexing the subject. This postverbal subjectindexing (henceforth PVSI) was investigated by Ross (1982) in languages of three NWS subgroups: Nehan/North-Bougainville, Piva-Bannoni, and MonoUruavan. Ross (1988: 250-251) later briefly noted a related phenomenon in two languages of the New Georgia/Isabel subgroup.

This article surveys PVSI in 20 languages and dialects across the entire NWS group, extending Ross's investigation by reexamining languages of the Nehan/North-Bougainville, Piva-Bannoni and Mono-Uruavan subgroups in the light of new data, as well as extending the survey into the two subgroups not investigated by Ross (1982): New Georgia/Isabel and Choiseul. On the basis of this survey a fuller picture of the synchronic phenomenon across the entire group is presented, prompting a reappraisal of Ross's analysis, including his hypothesis that a distinct clause structure is involved in the presence of PVSI, and allowing key problems not previously addressed to be investigated, including why the order of subject-indexing morphology and verb it accompanies is the reverse of the order of possessor-indexing morphology and noun in nominal constructions, and how distinct nominal categories of possession encoded by two separate possessor-indexing hosts could be reinterpreted as a verbal distinction of event type.

\section{Overview}

\subsection{Postverbal subject-indexing and possessive morphology in NWS}

In NWS, as elsewhere throughout Oceanic, dependent marking of arguments for core grammatical relations (i.e., case) plays a very limited role or is absent entirely. Instead, coding of grammatical relations depends on a combination of head marking, in the form of argument-indexing on the verb, and configurational structure, with the latter freer in languages displaying more indexing morphology, and more fixed in those displaying less.

The head marking of verbs for argument relations throughout Oceanic typically involves a clause structure reconstructable for Proto Oceanic, in which the verb is preceded by a particle or proclitic that encodes a modal or tense distinction (typically realis versus irrealis) and/or agrees with the person and number of the subject. The verb is followed by a suffix, enclitic or postposed particle that agrees with the person and number of the object: 


\section{(1) $\mathrm{MOD} / \mathrm{SBJ} . \mathrm{AGR}+\mathrm{V}+$ OBJ.AGR}

In all NWS languages, standard declarative clauses have this general structure, with the caveat that several have lost preverbal subject agreement, and several lack postverbal object agreement. This basic structure may be shown by Mono (Mono-Uruavan):

(2) Mono

$$
\begin{array}{llll}
\mathbf{i r}-\boldsymbol{i}=\text { lapu- } \boldsymbol{\varnothing} & g a & \text { taui } & k u i \\
\text { 3PL.SBJ-REAL=kill-3SG.OBJ } & \text { ABS } & \text { child } & \text { baby } \\
\text { 'They killed the infant child.' } & & & \\
\text { (Wheeler 1926: text 29) } & &
\end{array}
$$

However, many NWS languages including Mono also display an innovated strategy in which the subject is indexed by a postposed particle or enclitic:

(3) Mono

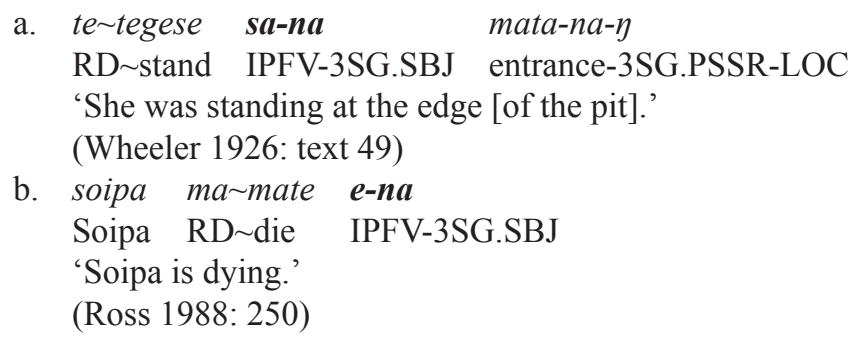

The morphology employed for postverbal subject-indexing in each language is also either employed in nominal constructions to index a possessor, or is derived from morphology that had that function at an earlier stage in the language. Compare (4) with (3) for Mono:

(4) Mono

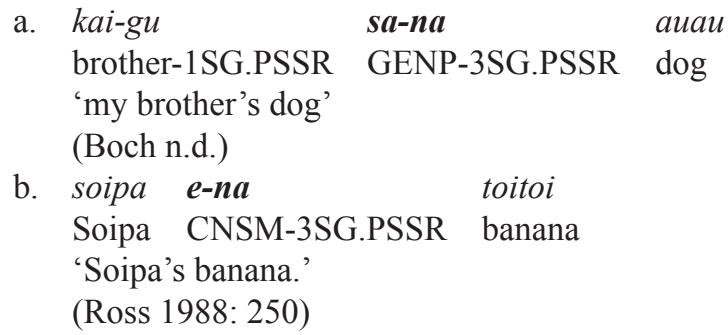

The morphology indexing subject in (3) and possessor in (4) reflects POc possessive morphology (Ross 1988: 112; Lynch 1996: 109). This nominal possessive morphology, from which relevant synchronic subject-indexing arose, can be reconstructed for Proto Northwest Solomonic (PNWS). 
As elsewhere in Oceanic, two nominal possessive constructions occur across NWS. In both, head marking indexes the person and number of the possessor. In one construction, termed "direct" possession in the Oceanist literature, suffixes indexing the possessor attach directly to the possessum noun, as with $k a i-g u$ in $(4 \mathrm{a})$. This prototypically marks inalienable possession. In the second construction, termed "indirect" possession, the possessor-indexing suffixes attach to a possessor-indexing host, as the highlighted morphology in (4) shows. These hosts are often referred to as possessive "classifiers" in the Oceanist literature, although Palmer and Brown (2007) argue that in many Oceanic languages they are not classifiers but the syntactic head of the NP in which they occur. Here they will be referred to using the neutral term "possessor-indexing host".

Mono has two such hosts. One encodes a nominal relationship in which the possessor has consumed, is consuming, or will consume the possessum (such as with items eaten or drunk), as in (4b). The other is a general default host encoding possessive relations that do not qualify for direct or "consumed" possessive marking.

Three indirect possessor-indexing hosts have been reconstructed for PNWS, shown in (5). Possessor-indexing suffixes can also be reconstructed, shown in Table 1.

(5) a. *na-

'general host'

b. *ye-

" "consumed" host'

c. $*_{s a-}$

'general host' (exact function unclear)

(Ross 1988: 185-186; Lynch 1996: 106-108)

In PNWS these suffixes participated in a direct possessive construction, as in (6a), and in an indirect construction, as in (6b) and (6c):

(6) a. *mata-gu

'my eye'

b. *na-gu ruma

'my house'

Table 1. PNWS possessor-indexing

\begin{tabular}{lllll}
\hline & $1 \mathrm{EXC}$ & $1 \mathrm{INC}$ & 2 & 3 \\
\hline $\mathrm{SG}$ & $*_{\text {-gu }}$ & - & $*_{\text {-mu }}$ & $*_{\text {-na }}$ \\
$\mathrm{PL}$ & $*_{- \text {mami }}$ & $*_{-d a}$ & $*_{- \text {miu }}$ & $*_{-d i}$ \\
\hline
\end{tabular}




$$
\begin{aligned}
& \text { *. } \quad \text { 'me-gu tohu } \\
& \text { my sugar cane (to eat)' }
\end{aligned}
$$

This nominal possessor-indexing system is repeated in most synchronic NWS languages using reflexes of the above morphology. The innovated PVSI morphology in NWS is derived historically from this indirect possessive morphology.

\subsection{The present investigation}

The phenomenon described above was first noted by Capell (1971: 276) (for languages of Buka) and Lincoln (1976: 427-428) (for Mono-Uruavan languages), but was not investigated in any detail until Ross (1982). Ross examined the structure of the verb complex ${ }^{3}$ in what are now regarded as three distinct first-order subgroups of NWS: Nehan/North Bougainville, Piva/Bannoni, and Mono-Uruavan (see Figure 1). Ross (1988) later noted PVSI in Roviana (New Georgia) and Cheke Holo (as Maringe) (Santa Isabel), thus drawing in one of the remaining two NWS first-order subgroups and postulating a PNWS origin to the construction (1988: 250-251). Of the other remaining first-order subgroup, Choiseul, Ross (1988: 251) states that no reflexes of PVSI have been found.

Ross $(1982,1988)$ is concerned primarily with structural rather than functional aspects of PVSI. He does discuss the sentence level functions of clauses displaying PVSI in Mono (recapitulative "thematic topic"; temporal adverbial clause; independent clause expressing habitual action) (1982: 37-40). However, Ross (1982) does not discuss the clause-internal function of the PVSI morphology, other than noting that the reduplication that often accompanies PVSI "distinguishes continuing action from [a] punctiliar or perfective event" (1982: 39). In his subsequent discussion of Roviana and Cheke Holo he says little about the function of PVSI, beyond identifying PVSI clauses in MonoUruavan and north Bougainville languages as "continuative" (1988: 251). In neither work does he discuss in detail the occurrence in PVSI of the two distinct nominal possessor-indexing hosts or examine their distribution or function.

Since Ross's work on this unusual phenomenon, more data has become available on NWS languages. On the basis of new materials, a detailed investigation of languages of the New Georgia/Isabel and Choiseul subgroups not examined by Ross (1982), and a more fine-grained investigation of the three subgroups surveyed by Ross (1982), this article expands on and reappraises Ross's work in four ways:

(7) a. Reappraising existing accounts of the structural characteristics of PVSI in the subgroups surveyed by Ross, and extending that survey 


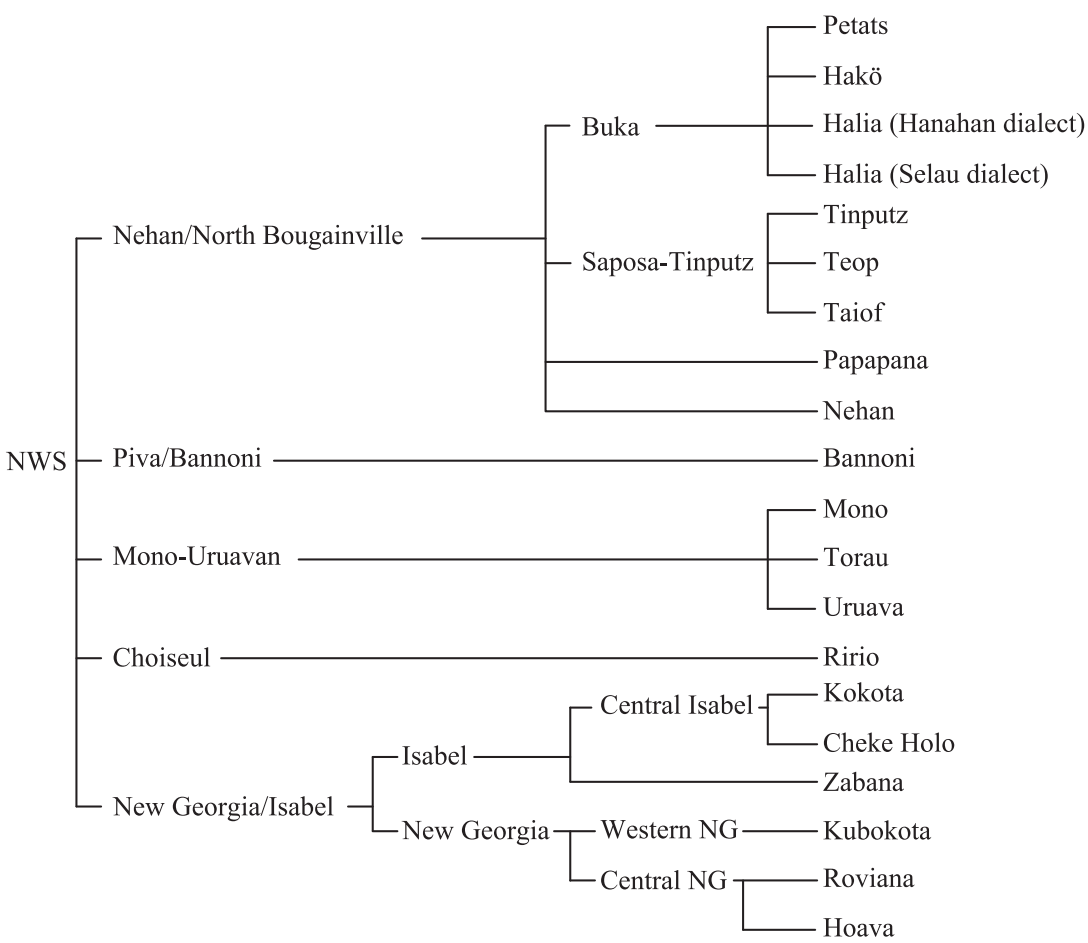

Figure 1. NWS subgroups with languages investigated here.

to the languages of the subgroups not investigated by Ross (1982), including testing whether or not PVSI involves a distinct construction across NWS as Ross (1982) suggested for the three subgroups investigated there.

b. Investigating in more detail the clause-internal functional characteristics of PVSI across NWS.

c. Investigating across NWS the verbal functional characteristics and distribution in PVSI of the two distinct nominal possessor-indexing hosts.

d. Reappraising Ross's proposed path of diachronic development of PVSI in the light of the findings of these investigations.

Twenty languages and dialects across NWS are surveyed here. The subgrouping assumed (based on Ross 1988: 215-217), with the languages surveyed, are presented in Figure 1.

The sampling method employed in selecting these languages was as follows. For the three subgroups investigated by Ross (1982), the best described lan- 
guages for each subgroup were included, along with less well described languages that appeared to pose problems or be divergent in some way. With the Nehan/North Bougainville subgroup, care was taken to represent key members of each second-order subgroup and both isolates. For the subgroups not investigated by Ross (1982) the three best described languages from each secondorder subgroup in New Georgia/Isabel were selected, along with one member of the little described Choiseul subgroup.

\section{Structural characteristics of PVSI across NWS}

Ross (1982: 6-7) treats clauses with PVSI as displaying an innovated clause structure, which he terms "Structure B", while clauses without PVSI reflect POc verb phrase structure, in his "Structure A". The present study found that one NWS language, Nehan, lacks PVSI entirely. Of the remaining languages, two distinct constructions, one with PVSI and one without, occur only in the lower-order Buka group within the Nehan/North Bougainville (NNB) network. For all other languages investigated, PVSI occurs optionally within the standard clause structure, co-occurring with preverbal subject-indexing if the language has it, at odds with Ross's claim.

\subsection{Nehan}

Nehan lacks postverbal subject-indexing employing possessive or former possessive morphology.

Ross $(1982: 14,36)$ analyzes one Nehan "relic" construction as displaying PVSI, involving an existential verb kae-, as in (8). In Ross's analysis, this verb requires a form expressing the subject. Ross analyzes kae- as displaying a reflex of an earlier existential verb *ka, with a reflex of the PNWS "consumed" host, which in (8) is possessor-indexed for 3SG. Ross analyzes the verb in (8) as reflecting pre-Nehan *ka e-na - an existential verb *ka followed by a $3 \mathrm{SG}$ possessor-indexed consumed host.

(8) Nehan

kalok kae-n tar tuy
K. exist-3SG.SBJ OBL ditch
'Kalok is in the ditch.'
(Ross 1982: 36)

More recent data does not support this hypothesis. Glennon and Glennon (1994: 91) analyze $\mathrm{kae}$ - as an alternate of $\mathrm{ka}$-, and analyze examples such as (9a) as involving a $3 \mathrm{SG}$ "object pronominal clitic" =in, part of a paradigm also 
including $=i s$ for $3 \mathrm{PL}$ animate objects, and $=i g$ for $3 \mathrm{PL}$ inanimate objects. They also note that this use of object forms also occurs with the negative existential tabo 'be absent', as in (9b).

(9) Nehan

a. $\boldsymbol{k} \boldsymbol{a}=\boldsymbol{i n} \quad i \quad$ um

exist=him/her/it LOC house

'He's in the house.'

(Glennon and Glennon 1994: 25)

b. k-e la baya tagin tar pipigogolik to

PRF-3SG.SBJ go see try OBL old.woman ART

no hue doh tabo=in

GENP.3SG.PSSR fire CNJ be.absent=him/her/it

'She went and checked to see if the old woman was at her fire but she wasn't there.'

(Glennon and Glennon 1994: 92)

Glennon and Glennon (2005) apparently subsequently revised their analysis, calling these pronominal clitics "Object Markers", implying that they belong to an agreement system.

Closer investigation of the Nehan data confirms Glennon and Glennon's original (1994) analysis. The forms they identify there as object pronominal clitics are weak accusative pronouns that encliticize to the preceding form. The forms of these clitics are a little more complex than Glennon and Glennon (1994) describe. For each, a series of phonologically determined allomorphs occur following the pattern $(i) C(i)$, where the initial and final vowels occur or are absent in certain environments.

More significantly for the present discussion, the forms involved cannot be associated with possessor-indexing, even historically, contrary to Ross (1982), for two reasons. First, they do not correspond to possessor-indexing in synchronic Nehan, which regularly reflects pre-Nehan possessor-indexing; and secondly they involve forms that can be seen to be synchronic clitic pronouns in other constructions.

Nehan has a set of nontopic pronouns that typically occur as enclitics on the preceding form. In non-third-person categories these express subjects or objects, as (10a) and (10b) show for 2SG. These pronouns are formally distinct from nominal possessor-indexing morphology, as (10c) shows.

(10) Nehan
a. ia $r-o$
$l a=a ?$
where LIG-2SG.SBJ
'Where are you going?'
(Glennon and Glennon 1994: 88) 


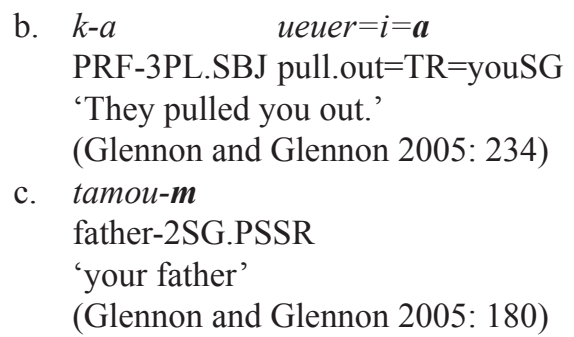

In non-third-person categories, clitic pronoun forms are invariant for subjects and objects, as (10a) and (10b) show. This is not, however, the case in third person, where distinct object and subject forms occur, as in (11a) and (11b). As with other person categories, these pronouns are formally distinct from nominal possessor-indexing, as shown by (11c).

(11) Nehan
a. $k-e$
$b a \eta=$ on $\quad r-e$
toko pe-r
PRF-3SG.SBJ see $=$ s/he/it LIG-3SG.SBJ sit ASP-LIG
derom
k.o.bird
'He saw the derom bird sitting.'
(Glennon and Glennon 1994: 60)
b. $k-a$
gatay huy pous=in
PRF-3PL.SBJ almost arrive kill=him/her/it
'They nearly killed him.'
(Todd 1978: 1182)
ART arm-2SG.PSSR-LIG child
'the child's arm'
c. a lima-na-r keketik
(Glennon and Glennon 1994: 49)

In $3 \mathrm{PL}$ the same distinction exists between subject and object forms as in $3 \mathrm{SG}$, as a comparison of (12) and (13) show. A further distinction exists in the 3PL objects between animate and inanimate referents, as in (13). Again the clitic pronoun forms, subject or object, are distinct from the corresponding nominal possessor-indexing as in (14).

(12) Nehan
a. $k-a$
baya $=$ sin toro rouot
PRF-3PL.SBJ see=they ART bamboo
'They saw the bamboo.'
(Glennon and Glennon 1994: 83)
b. k-a tina kout=ini=sin etie
PRF-3PL.SBJ break.apart cut=him/her/it=they there


'They cut it there.'

(Glennon and Glennon 1994: 62)

(13) Nehan

a. a torikue a touono-r hueit ura matoto ART two or ART three-LIG pig 3PC.SBJ be.adequate

$[r-a$ ein $=$ is]

LIG-3PL.SBJ eat=them.ANIM

'Two or three pigs are enough for them to eat them.' (Todd 1978: 1224)

b. ..r-a susuk=ig tar usiri-na-r LIG-3PL.SBJ sew=them.INANIM OBL midrib-3SG.PSSR-LIG kamana-na iatou leaf-3SG.PSSR sago.palm

'. . [ [which] they sew them with the midrib of a sago palm leaf.' (Todd 1978: 1219)

c. $k$ - $a \quad$ uana $=i s i=\sin$

PRF-3PL.SBJ shoot=them.ANIM=they

'They shot them.'

(Glennon and Glennon 1994: 79)

d. a ni-eini-ni=ne $\quad[r-a \quad$ kale

ART NMLZ-eat-PL=here LIG-3PL.SBJ take

tur $=$ igi $i=\sin i$ uanaran $]$

stand=them.INANIM=they LOC U.

'the foods [which] they got them from Uanaran'

(Glennon and Glennon 1994: 89)

(14) Nehan

$$
r-a \quad t u \text {-sia }
$$

LIG-ART child-3PL.PSSR

'their children'

(Todd 1978: 1190)

The full set of clitic pronouns and corresponding nominal possessor-indexing suffixes are shown in Table 2.

The clitic pronoun forms expressing third person objects are confined to arguments with that grammatical relation and are therefore weak accusative pronouns. The nonobject forms occur in all other contexts, including, for example, as possessors, as in (15), and are therefore nonaccusative.

(15) Nehan

a. kalo- $m u=\boldsymbol{a}$

friend-2SG.PSSR=youSG

'your friend'

(Glennon and Glennon 1994) 
Table 2. Nehan clitic pronouns and possessor-indexing suffixes

\begin{tabular}{|c|c|c|c|}
\hline & $\begin{array}{l}\text { nonaccusative clitic } \\
\text { pronouns }\end{array}$ & $\begin{array}{l}\text { accusative clitic } \\
\text { pronouns }\end{array}$ & possessor-indexing suffixes \\
\hline $1 \mathrm{SG}$ & \multicolumn{2}{|c|}{$=O$} & $-g \sim-g u$ \\
\hline 1EXCPL & \multicolumn{2}{|c|}{$=$ eim } & $-m i(u)$ \\
\hline 1INCPL & \multicolumn{2}{|c|}{$=e i g$} & $-g i(g)$ \\
\hline $2 \mathrm{SG}$ & \multicolumn{2}{|c|}{$=a$} & $-\eta \sim-m(u)$ \\
\hline $2 \mathrm{PL}$ & \multicolumn{2}{|c|}{$=$ oum } & $-m i(u)$ \\
\hline $3 \mathrm{SG}$ & $=o n(o)$ & $=(i) n(i)$ & $-n(a)$ \\
\hline 3PL animate & \multirow{2}{*}{$=\sin (o)$} & $=(i) s(i)$ & \multirow{2}{*}{$-s(i(a))$} \\
\hline 3PL inanimate & & $=(i) g(i)$ & \\
\hline
\end{tabular}

b. tina- $n=$ on

mother-3SG.PSSR=s/he/it

'her mother'

(Todd 1978: 1224)

c. $o \quad t u-s i a=$ sino

ART child-3PL.PSSR=they

'their children'

(Todd 1978: 1225)

In the existential clauses in (8) and (9a) the sole argument is not expressed postverbally using possessive morphology, but using a clitic pronoun. When that argument is non-third person, one of the functionally invariant clitic pronoun forms occurs, as in (16).

(16) Nehan

$\begin{array}{llll}\text { ing- } a & k a e=a & \text { tar } & \text { tuy } \\ \text { TOP-youSG } & \text { exist=youSG } & \text { OBL } & \text { ditch }\end{array}$

'You are in the ditch.'

(Ross n.d.)

When that argument is third person, it is the accusative clitic form that is used, as seen in the singular in (8) and (9a) and in the plural in (17).

(17) Nehan

$\begin{array}{llll}\text { ginin } & k a e=i g & \text { te } & \text { na }\end{array}$

TOP.DEM exist=themINANIM OBL GENP.3SG.PSSR village 


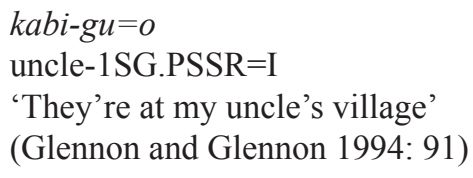

Existential constructions often display a preposed topic NP coreferent with the argument expressed by the enclitic pronoun, though this is not obligatory, as (9) shows. Preposed topics in this construction parallel the occurrence of preposed topics coreferent with object clitic pronouns in normal transitive clauses, as in (18).

$$
\begin{array}{lll}
\text { (18) } & \text { ing }-\boldsymbol{o} \quad \text { deh }=e & \text { mahiy }=i=\boldsymbol{o} \\
\text { TOP-I } & \text { really=3SG.SBJ } & \text { hurt=TR=I } \\
\text { 'It's really hurting me.' } &
\end{array}
$$

Unlike transitive or nonexistential intransitive constructions, the existential construction in Nehan lacks preverbal subject agreement seen throughout (10) to (13) and in (18) that is obligatory in nonexistential declarative clauses. The Nehan existential construction in (8) and (9) involves an intransitive verb whose sole argument is expressed using an accusative pronoun, and is not marked by preverbal subject agreement. It is treated in the same way as the $\mathrm{O}$ of a transitive construction, rather than the $\mathrm{A}$. The language therefore displays a split-S phenomenon in which the sole argument of an existential verb is treated in the same way as the object of a transitive clause, while the sole argument of all other intransitive verbs are treated in the same way as an A. However, crucially for the present discussion, the construction does not involve argument-indexing using synchronic possessive morphology, or reflexes of former possessive morphology, so lacks PVSI.

\subsection{Languages with a distinct PVSI clause structure}

With the exception of the Selau dialect of Halia (see below), languages of the Buka group display two distinct clause structures corresponding to Ross's Structures A and B. The key characteristics of Structure A are: a) the retention of preverbal subject-indexing; b) the presence of a preverbal modal particle associated with subject-indexing; and c) the lack of innovated PVSI. The key characteristics of Structure B are: a) the presence of PVSI; b) the replacement of preverbal subject-indexing with an invariant predicate marker $e$, generalized from the preverbal 3SG subject agreement; and c) the absence of the preverbal modal particle associated with subject-indexing in Structure A.

(19) Petats

$$
\begin{aligned}
& \text { a. ejau } \boldsymbol{e} \text { hula yot } \\
& \text { s/he REAL.3SG.SBJ everywhere look }
\end{aligned}
$$


'He looked everywhere.'

(Ruffolo n.d.)

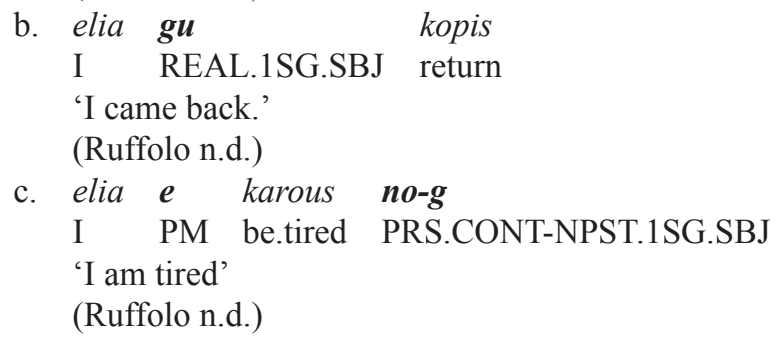

\subsection{Optional PVSI with general clause structure}

Languages in all other NWS groups, including languages from all other NNB languages, do not display distinct Structures A and B. Clauses with PVSI display the same preverbal subject and modal marking as clauses without PVSI. In these languages, preverbal subject-indexing may be omitted in certain discourse contexts, and this applies equally to clauses with and without PVSI. Clauses with PVSI are therefore distinguishable from clauses without only by the presence of the PVSI morphology itself, and therefore do not constitute a distinct clause structure.

Several of these languages have lost preverbal subject-indexing historically. In these languages, clauses with and without PVSI lack preverbal subjectindexing and are therefore again only distinguished by the postverbal morphology itself, and do not represent a distinct construction.

3.3.1. NNB - Buka group - Halia (Selau dialect). Unlike Petats, Hakö and the Hanahan dialect of Halia, which do display a distinct PVSI construction, Halia's Selau dialect does not display preverbal subject-indexing in realis clauses, although residual preverbal agreement does occur in irrealis clauses. In realis clauses Selau has generalized the predicate marker $e$ to all clauses, with or without PVSI:

(20) Selau
a. $\boldsymbol{e}$ mate narawa
PM die yesterday
'He died yesterday.'
(Ross n.d.)
b. ala $\boldsymbol{e}$ nu-ia man osono $i$ nolaha
I PM eat-3SG.OBJ some taro LOC yesterday
'I ate some taro yesterday.'
(Ross n.d.) 


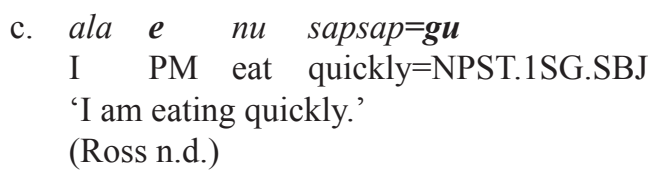

However, it seems reasonable to hypothesize that Selau independently lost its preverbal subject-indexing relatively recently, and that pre-Selau resembled Hanahan in displaying two distinct constructions, in which the PVSI construction had generalized the preverbal $3 \mathrm{SG}$ subject marker $e$ as a predicate marker. Selau has taken this one step further by generalizing this predicate marker to all realis clauses, neutralizing a distinction between a Structure A and Structure B present in pre-Selau.

3.3.2. NNB - Saposa-Tinputz group. Languages of NNB network's Saposa-Tinputz group have lost all (or almost all) preverbal subject-indexing. In these languages, PVSI occurs in clauses that share all other characteristics with clauses lacking the postverbal morphology. Clauses with and without PVSI lack preverbal subject-indexing, but both display preverbal modal particles.

Two of the Saposa-Tinputz languages investigated, Teop and Tinputz, display no preverbal subject-indexing:

(21) Teop

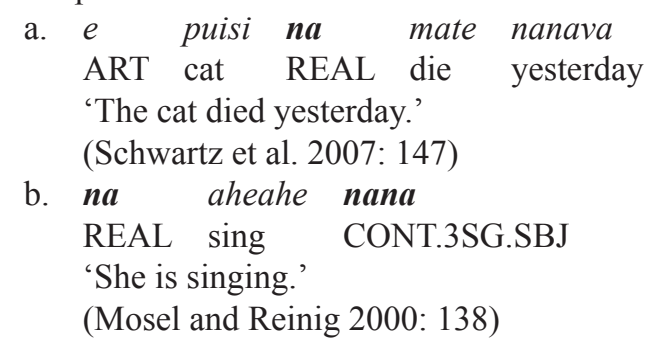

The third Saposa-Tinputz language investigated, Taiof, has lost all preverbal subject-indexing except for the 3PL in realis. All other person/number categories occur with the otherwise invariant realis marker $t o$. The 3PL realis form is $t i$, representing realis to marked with the 3PL subject agreement marker $i$ seen elsewhere in NNB. This distribution occurs equally in clauses with and without PVSI:

(22) Taiof

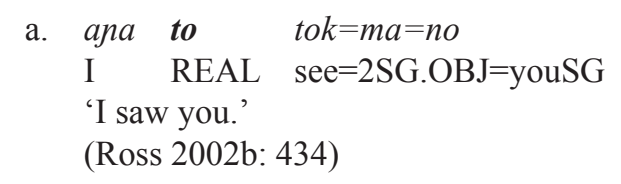




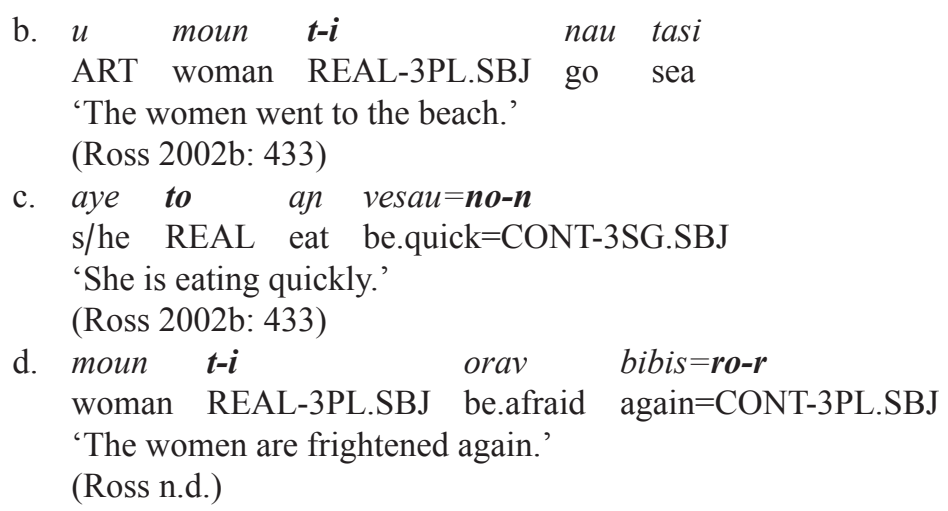

3.3.3. NNB - Papapana. Papapana has retained preverbal subjectindexing, which occurs in clauses with and without PVSI. Clauses with PVSI are distinguished only by the presence of that morphology and no distinct construction exists.

(23) Papapana

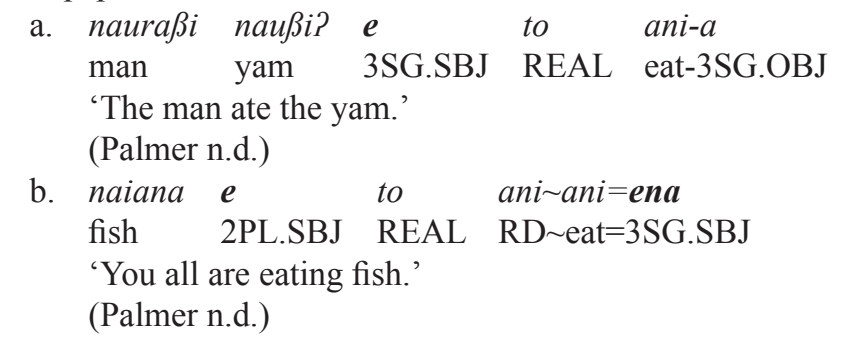

3.3.4. Piva/Bannoni. Declarative clauses in Bannoni display preverbal subject agreement, while clauses displaying PVSI do not. However, PVSI in Bannoni occurs only in clauses expressing permission or prohibition. (Lincoln 1976: 84, 88-89, 132-134; Lynch and Ross 2002: 449; Ross 1982: 12) These clauses functionally resemble imperative clauses, and Bannoni imperatives formally lack preverbal subject-indexing. Bannoni permissive and prohibitive clauses therefore resemble other imperative clauses in lacking preverbal subject-indexing, are not structurally distinct from other imperatives, and do not represent a distinct clause structure.

(24) Bannoni
a. tai nau
go DIR
'Go away.'
(Ross n.d.) 
b. tai ye-m

go PRM/PHB-2SG.SBJ

'You may go'

(Lincoln 1976: 89; Lynch and Ross 2002: 449)

pa ye-m pa pats

youSG NEG PRM/PHB-2SG.SBJ RD pick LOC-cluster

'Don't pick [mangoes] from a cluster.'

(Lincoln 1976: 133)

3.3.5. Mono-Uruavan. The three Mono-Uruavan languages display preverbal subject-indexing and modal morphology whether or not the clause also carries PVSI:

(25) Mono

a. $\quad$-na $=$ segulu $\quad$ au

'Stand on [them].'

(Wheeler 1926: text 48)

b. $\boldsymbol{o}-\boldsymbol{n a}=s o \sim s o a-i-a \quad s \boldsymbol{s}-\boldsymbol{y}$

2SG.SBJ-IRR=RD take-TR-3SG.OBJ IPFV-2SG.SBJ

'You are always to look after it.'

(Wheeler 1926: text 49)

In Torau, realis is the default modality, and clauses only carry preverbal realis subject-indexing particles if they are required for one of a number of morphosyntactic reasons, including the absence of subject-indexing elsewhere in the clause, or the need to host a past tense marker that suffixes to the modal/subject particle. (Palmer 2007a: 504) This means that most realis clauses with PVSI lack overt preverbal subject-indexing. However, this does not constitute a distinct clause structure with PVSI, as irrealis clauses always carry a preverbal subject-indexing particle whether or not PVSI is present, and realis clauses do so when past tense marking is required.

3.3.6. Choiseul. Ross (1988: 251) observes that no reflexes of PVSI have been found in Choiseul languages. However, a closer investigation of the data reveals that PVSI does occur in this group. Choiseul languages, represented in the sample by Ririo, display a unique distribution of PVSI: it is confined to negative clauses. In Ririo this extends to clauses expressing negative propositions without negative morphology. Clauses displaying formal negation have a distinct structure in which the subject is indexed postverbally, and a negative particle occurs in place of the preverbal modal/subject-indexing particle seen in clauses expressing positive propositions. These facts combine to give the 
superficial appearance of a distinct clause structure with PVSI agreeing with Ross's "Structure B", as a comparison of (26a) and (26b) show.

(26) Ririo

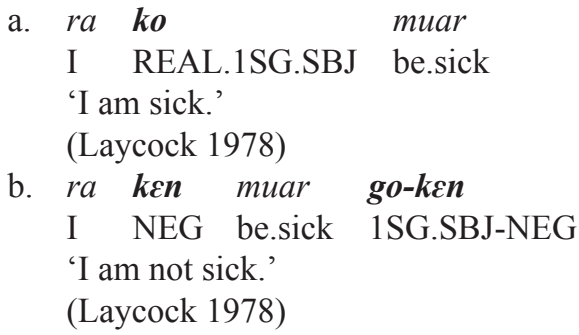

PVSI is not confined to clauses marked with the general negator $k \varepsilon n$ in place of preverbal subject-indexing. It also occurs in clauses with at least one other, more specific negative particle in place of preverbal subject-indexing. In this context the final negative particle is optional:

\section{(27) Ririo}

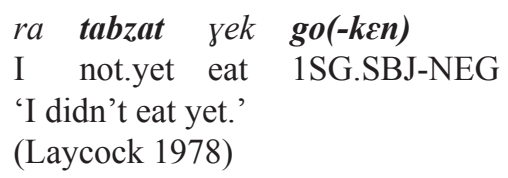

However, PVSI is not entirely confined to clauses resembling (26b) or (27). Clause (26b) expresses a negative proposition by means of overtly negating a verb expressing a positive proposition. At least one verb occurs in Ririo that itself expresses a negative proposition. This verb, keso 'not want', does not require overt formal negation, and the negative clause structure in (26b) does not occur. Instead, the verb occurs with a preverbal modal/subject particle in the same way as clauses with any other verb. However, because it expresses a negative proposition, the clause does display PVSI. Examples (28a) and (28b) show PVSI with an overtly negated positive desiderative verb sio? and with the non-negated negative desiderative verb kess.

(28) Ririo
a. ra ken sio? go-ken guel zen
I NEG want 1SG.SBJ-NEG woman DEM
'I don't like this woman.'
(Laycock 1978)
b. ra ko keso go guel zen
I REAL.1SG.SBJ not.want 1SG.SBJ woman DEM
'I don't like this woman.'
(Laycock 1978)


The clause structure distinction seen in (26) and (28) is therefore a distinction between formally negated and non-negated clauses, independent of the presence of PVSI.

3.3.7. Santa Isabel. Two of the three Santa Isabel languages investigated, Zabana and Kokota, display preverbal subject-indexing. In both, PVSI occurs as optional additional marking in the standard clause structure, co-occurring with preverbal subject-indexing and modal particles:

(29) Kokota
a. $\boldsymbol{n}$ - $\boldsymbol{a}$
babao
REAL-1.SBJ be.tired
'I'm tired.'
(Palmer 2002; 2009)
b. $\boldsymbol{n}$-a babao no-gu
REAL-1.SBJ be.tired INTNS-1SG.SBJ
'I'm really tired.'
(Palmer 2002; 2009)

The third Santa Isabel language investigated, Cheke Holo has lost all preverbal subject-indexing. This applies equally to clauses with and without PVSI, so clauses with PVSI are again structurally indistinguishable from those without except for the presence or absence of the postverbal morphology itself.

(30) Cheke Holo

a. mana tei hila

he go PRF

'he has already gone.'

(White et al. 1988)
b. iara tei no-gu buala
I go INTNS-1SG.SBJ PNLOC
'I'm going to Buala.'

(White et al. 1988: xx)

3.3.8. New Georgia. In nominal possessive morphology the New Georgia languages share an innovated set of synchronically monomorphemic general indirect possessor-indexing forms reconstructable for Proto New Georgia. These innovated forms occur in both nominal possession and PVSI.

Table 3. Innovated Proto New Georgia general indirect possessor-indexing

\begin{tabular}{lllll}
\hline & $1 \mathrm{EXC}$ & $1 \mathrm{INC}$ & 2 & 3 \\
\hline $\mathrm{SG}$ & * $_{\text {gua }}$ & - & $*_{\text {mua }}$ & $*_{\text {nana }}$ \\
$\mathrm{PL}$ & *mami & *nada $_{\text {nad }}$ & $*_{\text {mia }}$ & $*$ dia \\
\hline
\end{tabular}


Languages from a probable western subgroup within the New Georgia grouping, represented in the survey by Kubokota, display preverbal subjectindexing, which occurs along with modal marking in clauses with or without PVSI:

(31) Kubokota

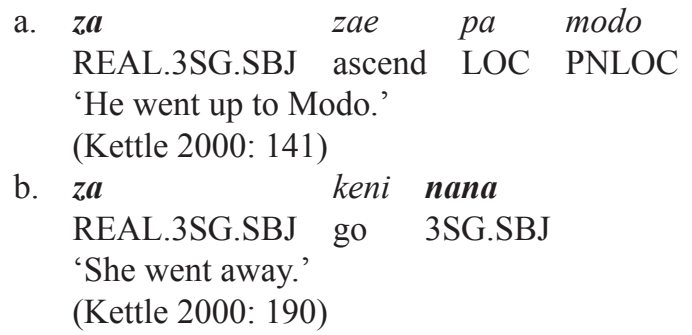

Languages from a probable central subgroup, represented in the survey by Hoava and Roviana, have lost preverbal subject-indexing. In these languages, PVSI again occurs in clauses that are otherwise structurally indistinguishable from those without PVSI:

(32) Hoava
a. vose yore atu ria
paddle descend thither they
'They paddled down (to you).'
(Davis 2003: 119)
b. vose vose pule la nana
RD paddle return go PROG.3SG.SBJ
'He was paddling back.'
(Davis 2003: 172)

\subsection{Summary of evidence on a distinct clause structure with postverbal subject agreement}

PVSI occurs in clauses with a structure distinct from that of clauses without PVSI only in the lower-order Buka group of NNB. All other subgroups of NWS, including other groups within NNB, employ PVSI as optional additional morphology within standard clause structure.

\section{Clause-internal functional characteristics of PVSI in synchronic NWS}

Ross (1982) is concerned primarily with the synchronic structure and diachronic development of the morphosyntax of verbal constructions in the NWS languages of Bougainville and Buka. He does not investigate the functional 
characteristics of PVSI in detail. This section discusses the functional characteristics of PVSI in all 20 surveyed languages excluding Nehan, which lacks PVSI.

\subsection{NNB-Buka group}

In all surveyed languages and dialects of the Buka group, PVSI occurs in clauses expressing nonpast events, while clauses without PVSI express events located in the past or at some distant unspecified time.

(33) Petats formerly I 1SG.SBJ be-LOC LOC Petats but now elia $e \quad k a-u=g u \quad i \quad$ pororan

I PM be-LOC=NPST.1SG.SBJ LOC Pororan

'Formerly I lived at Petats but now I live at Pororan.'

(Ross 1982: 17)

b. elia $e$ la gon-me $=\boldsymbol{g}$ - $u \quad e$

I PM go together-APPL=NPST.1SG.SBJ-FUT ART

haroman $i \quad$ latu

Haroman LOC bush

'I will go with Haroman through the bush.'

(Ross 1988: 252)

Reflexes of PNWS possessor-indexing hosts are typically absent from PVSI in the Buka group. Instead, the indexing suffixes attach directly to the verb. In Petats and Hakö a reflex of the old host has developed a separate function to that of the subject-indexing itself. In these languages no- marks continuous aspect in present tense. In (34a) the indexing suffix occurs without a host in a clause expressing a punctual event, while in (34b), the host does occur in a clause expressing an ongoing event in the present (see also [19]). A reanalysis of PVSI as tense marking appears to have prompted a reanalysis of the host itself as a marker of continuous aspect in Petats and Hakö, functionally dissociating the host from the indexing. In Halia (Hanahan and Selau) reflexes of the hosts are entirely absent in all contexts, as in (35), even in clauses aspectually comparable to that in (34b).

(34) Petats

a. eiau e sinak $=\boldsymbol{n a}=u \quad$ elia

he PM hit=NPST.3SG.SBJ=FUT I

'He will strike me.'

(Capell n.d.: 7) 


\section{2. $N N B-$ Papapana}

PVSI in Papapana occurs in clauses expressing ongoing states and events in the past, future or present as in (37a) to (37c). Clauses expressing punctual events lack PVSI ([37d]). PVSI marks ongoing dynamic events (see [23b]) and existential and stative events ([37a] to [37c]). The expression of habitual aspect in Papapana is not known, so it is not clear whether PVSI is confined to continuous aspect or marks all imperfective. In the absence of evidence of the habitual, it is assumed to encode continuous aspect.

(37) Papapana

a. roroßana mi pe po po=mani

Rorovana 1EXCPL.SBJ PRF RD be.at=IPFV.1EXCPL.SBJ

'We used to live at Rorovana.'

(Palmer n.d.)

b. $a i-n a b u=$ ena

NEG-heavy=IPFV.3SG.SBJ

'It is not heavy.'

(Allen and Hurd 1963: 121)

c. buka o no po=omu- $i$

Buka 2SG.SBJ IRR be.at=IPFV.2SG.SBJ-?

'You will stay at Buka.'

(Palmer n.d.)

d. naunaua $e$ to mate

yesterday 3SG.SBJ REAL die

'Yesterday he died.'

(Palmer n.d.)

\subsection{NNB - Saposa-Tinputz group}

For Taiof (Ross 2002b: 433) and Teop (Schwartz et al. 2007; Mosel and Reinig 2000; Mosel and Thiesen 2007) PVSI has been analyzed as encoding imperfective aspect. Its function in Tinputz has not previously been analyzed. In all three languages it is attested with ongoing states and dynamic events in any temporal or modal frame, as in (38) (see also [22c] and [22d] and [47] for Taiof, and [48] and [49] for Tinputz). In Taiof and Teop habitual aspect is encoded separately. This may co-occur with PVSI, giving a sense of the subject habitually engaging in ongoing events, as in (39a), but need not, giving a sense of habitual performance of a punctual event, as in (39b). As PVSI does not itself encode habitual, it therefore encodes continuous rather than imperfective 
aspect. The expression of habitual aspect in Tinputz is not known, but as it belongs to the same subgroup as Teop and Taiof the same situation is assumed to exist.

(38) Teop
a. ean sa paa rake haa bata maa
youSG NEG PST like NEG SIM DIR
nom a beiko te-naa
CONT.1EXC/2.SBJ ART child LOC-I

'At the same time you did not like my child.'

(Mosel and Reinig 2000: 133)

b. ena na memea nom

I REAL be.thirsty CONT.1EXC/2.SBJ

'I am thirsty'

(Carter 1952: 239)

c. na tei nana te- $a$ inu a rutaa

REAL be CONT.3SG.SBJ LOC-ART house ART small

'He stays in a small house.'

(Mosel and Reinig 2000: 137)

d. e kakato na ani nana

ART Kakato REAL eat CONT.3SG.SBJ

'Kakato is eating the fish.'

(Mosel and Thiesen 2007)

e. pasi nomaa rori subunubu

FUT come CONT.3PL.SBJ tomorrow

'They will come tomorrow'

(Schwartz et al. 2007: 156)

(39) Taiof

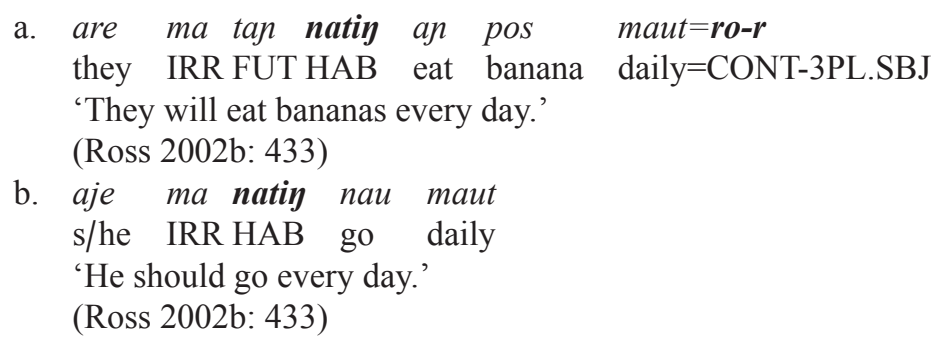

In Teop the subject-indexing function of PVSI is weakening: person and number distinctions in first exclusive and second person have been neutralized and are expressed by the form nom, as (38a) and (38b) show. Taiof and Tinputz have retained distinct forms for each person/number category. 


\subsection{Piva|Bannoni}

PVSI in Bannoni occurs only in clauses expressing permission or prohibition (see Section 3.3.5). It therefore marks the indexed argument as the subject of a permission or prohibition.

\subsection{Mono-Uruavan}

PVSI in Mono-Uruavan expresses ongoing states and events in any temporal or modal frame, and with verbs of all kinds, including stative, existential, experiencer, psych, and postural verbs, as well as activity and achievement verbs. (See Palmer 2007a for a detailed discussion of PVSI aspectual semantics in Torau.)

(40) Mono

a. nitu go golu sa-na eeta-na

spirit RD eat IPFV-3SG.SBJ be.raw-3SG.PSSR

'The spirit kept on eating them raw.'

(Wheeler 1926: text 18)

b. ba baeni sa-may

RD ask IPFV-1EXC.SBJ

'We are praying.'

(Boch n.d.)

(41) Mono

a. talaiva nihe hu hulau sa-ria

women snake RD fear IPFV-3PL.SBJ

'Women are frightened of snakes.'

(Ross 1988: 250)

b. kirikoputu tivo-na au sa-ria

Kirikoputu RFL-3SG.PSSR exist IPFV-3PL.SBJ

'Kirikoputu was alone.'

(Wheeler 1926: text 1)

c. boitalu hanua=ay alu roro- $i-\varnothing-a$

formerly people=LOC Alu see-TR-3SG.OBJ-thither

sa-ria ga niunu

IPFV-3PL.SBJ ABS coconut

'Formerly the Alu people could see the coconut palm.'

(Ross 1982: 40)

However, unlike other NWS languages, PVSI in Mono-Uruavan also marks habitual aspect, as shown in (42). It therefore encodes full imperfective aspect. 
(42) Mono

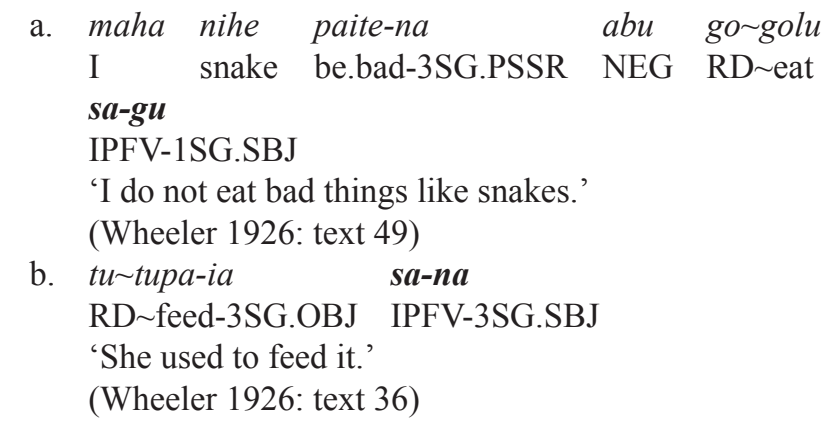

\subsection{Choiseul}

PVSI in Ririo occurs in clauses expressing a negative proposition both in formally negated clauses and in clauses with a verb that expresses a negative proposition (see Section 3.3.7). PVSI is confined to and obligatory in clauses of this kind. It therefore marks the indexed argument as the subject of a negative proposition.

\subsection{Santa Isabel - Zabana}

Fitzsimons (1989: 108) argues that PVSI in Zabana encodes "middle voice", functioning "to indicate that the action affects the actor." Evidence from Zabana informants confirms that PVSI is confined to clauses expressing events in which the subject is affected in some way.

PVSI in Zabana cannot occur indexing the A of a transitive verb or the $\mathrm{S}$ of an unergative intransitive verb expressing an event which does not directly affect the subject. Instead, it occurs only indexing the subject of unaccusative verbs, such as those expressing events that are beyond the control of the subject (as in [43a]), or unergative verbs in which the subject's actions reflexively affect them in some way, either physically or psychologically (as in [43b]), where the subject has some of the characteristics of a patient or theme as well as those of an agent. This includes verbs expressing physical and psychological states, changes in location, and activities that affect the subject such as studying and eating. With most verbs PVSI is optional, and has the function of emphasizing the affect of the event on the subject.

(43) Zabana
a. puna mau
ye-mai
$m a-m u$
very be.afraid AFFECT-1EXC.SBJ ?-CONT
'We were very frightened.'
(Fitzsimons 1989: 109) 
b.

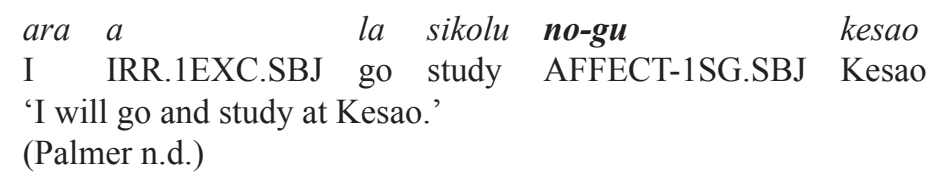

\subsection{Santa Isabel - Kokota and Cheke Holo}

PVSI does not have a straightforward aspectual function in Kokota and Cheke Holo. Instead, it marks events as having "high saliency or immediacy" in Kokota (Palmer 2009: 260), while in Cheke Holo "intensifying the degree of involvement of the subject" (White et al. 1988: xix). In realis clauses PVSI indicates that the event or state pertains at the moment of speaking, as in (44a). In irrealis clauses it indicates that the event is about to occur ([44b]). In imperative clauses it indicates that the event should occur immediately ([44c]). If another temporal frame is established, the event had or will have high saliency at the moment indicated ([44d]). No semantic restrictions exist on which verbs can be marked with PVSI in Kokota and Cheke Holo, the indexing occurring with unergative and unaccusative intransitive verbs, as well as transitive verbs, as shown by (44a).

(44) Kokota

a. $\quad$ ara $n-a \quad g o=$ no- $\boldsymbol{g} \boldsymbol{u}=n i$

I REAL-1.SBJ be.insensible $=$ INTNS-1SG.SBJ $=3$ SG.OBJ

naja-na-na manei

name-3SG.PSSR-DEM s/he

'I don't know his name.'

(Palmer 2009)

b. maneri Ø-e zaho no-di

they IRR-3.SBJ go INTNS-3PL.SBJ

'They are about to go [right now].'

(Palmer 2009)

c. zaho по-и

go INTNS-2SG.SBJ

'Go away [right now]!'

(Palmer 2009)

d. ka-t-au-ana ge la lehe no-gu

LOC-SBD-exist-that NT go die INTNS-1SG.SBJ

bo-sini

CNTRST-FOC

'At that [moment] I nearly died.'

(Palmer 2009) 


\subsection{New Georgia}

PVSI in New Georgia languages is not linked to aspect. Instead, it indexes undergoer and experiencer subjects. Kettle (2000: 196-198) analyzes postverbal argument-indexing morphology in Kubokota as marking durative aspect. Chambers (2009: 139-143) demonstrates that the morphology is not linked to aspect in Kubokota as it occurs in clauses with a range of aspectual characteristics, including those referring to punctual perfective events, as in (45a), and many clearly imperfective clauses lack it, as in the first clause in (45b).

(45) Kubokota

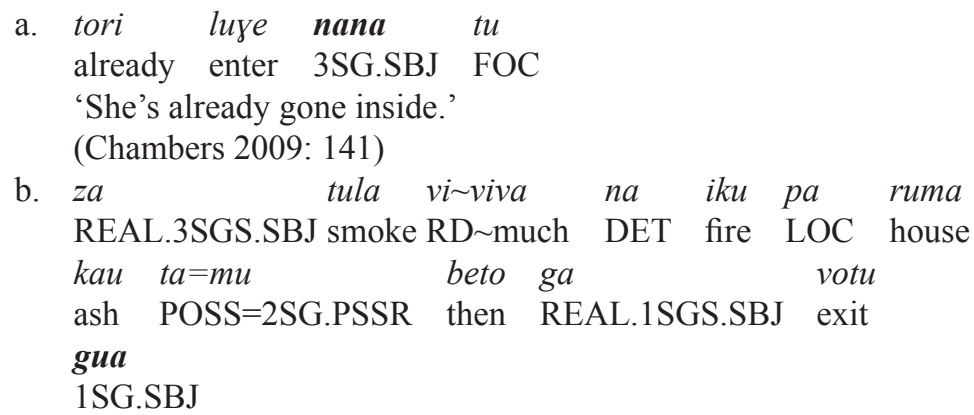

'The fire in your kitchen is smoking a lot so I've come outside.' (Chambers 2009: 140)

Chambers demonstrates instead that the function of PVSI in Kubokota is to index subjects with the semantic role of patient, theme or experiencer. In most instances it occurs with intransitive verbs, including existential verbs, as in (46a), and verbs whose subject is in a state ([46b]) or location ([46c]), or changes state ([46d]) or location ([46e] and [45]) (Chambers 2009: 139). PVSI also indexes experiencer subjects of transitive experiencer verbs, as in (46f) (Chambers 2009: 141-142). The same situation applies in Hoava and Roviana. Davis (2003: 174) argues that Hoava PVSI has a function "analogous to middle voice" and occurs only with verbs of emotion and perception; verbs of self-grooming, and events where the subject undergoes change of state, location or posture. The data shows it also occurs with existential verbs. For Roviana, Corston-Oliver (2002: 479) argues PVSI indexes the S argument of an intransitive clause. However, available data shows Roviana resembling Hoava, with PVSI occurring with postural and existential verbs and verbs of motion and physical sensation. 
(46) Kubokota

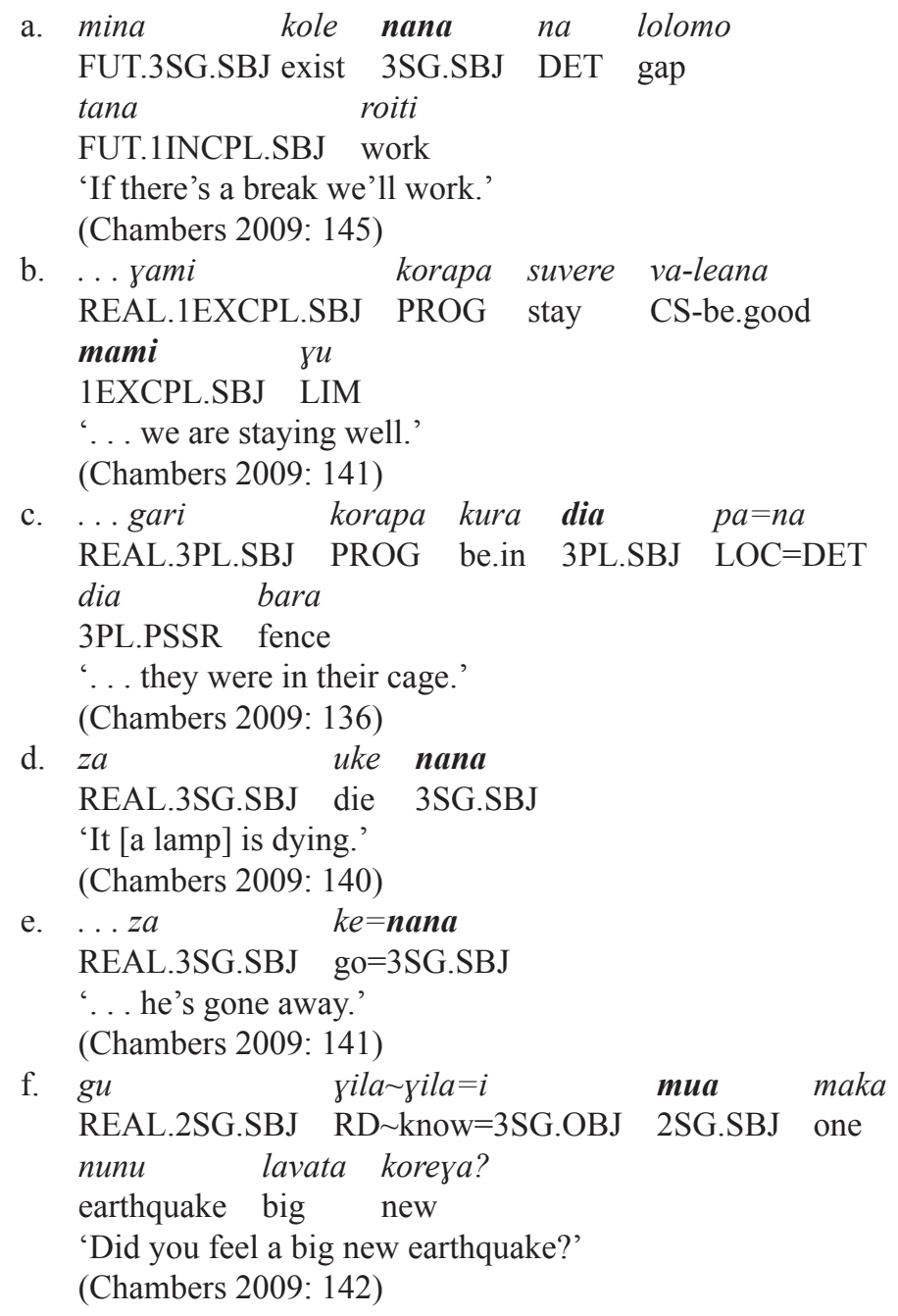

Kettle (2000: 193-195) argues that as well as indexing intransitive subjects, postverbal indexing also indexes the object of transitive verbs, concluding therefore that it indexes the absolutive argument. Chambers (2009: 139) found that PVSI does not index the object, and that the examples on which Kettle based this conclusion were either misanalyzed instances of nominal possession or were rejected as ungrammatical by speakers. 


\subsection{Summary of synchronic function of PVSI}

The synchronic functional characteristics of PVSI are summarized in Tables 3 and 4 .

As Table 4 shows, PVSI encodes imperfective or continuous aspect in two of the five first-order NWS subgroups. No other function is represented in more than one first-order subgroup, and the functions in the other first-order subgroups involve plausible semantic extensions or restrictions of this aspectual function. The originating reverbalized construction therefore appears to have expressed ongoing events and states. The data summarized in Table 5 indicates that the morphology in the originating construction indexed subject.

Table 4. The function of PVSI in synchronic NWS

\begin{tabular}{|c|c|c|c|}
\hline \multirow{5}{*}{$\begin{array}{l}\text { Nehan/North } \\
\text { Bougainville }\end{array}$} & \multicolumn{2}{|c|}{ Nehan } & - \\
\hline & \multirow{2}{*}{ Buka } & Petats and Hakö & $\begin{array}{l}\text { nonpast tense (without } n o-\text { ); } \\
\text { present continuous (with } n o-\text { ) }\end{array}$ \\
\hline & & Halia (Hanahan and Selau) & nonpast tense \\
\hline & \multicolumn{2}{|c|}{ Papapana } & continuous aspect \\
\hline & \multicolumn{2}{|c|}{ Saposa/Tinputz } & continuous aspect \\
\hline \multicolumn{3}{|l|}{ Piva/Bannoni } & permission/prohibition \\
\hline \multicolumn{3}{|l|}{ Mono-Uruavan } & imperfective aspect \\
\hline \multicolumn{3}{|l|}{ Choiseul } & negative propositions \\
\hline \multirow{3}{*}{$\begin{array}{l}\text { New Georgia/ } \\
\text { Isabel }\end{array}$} & \multirow{2}{*}{ Isabel } & Zabana & subject affected by event \\
\hline & & Central & involvement of subject intensified \\
\hline & \multicolumn{2}{|c|}{ New Georgia } & subject is undergoer or experiencer \\
\hline
\end{tabular}

Table 5. Arguments indexed by postverbal "possessive" morphology in synchronic NWS

Nehan/North Bougainville

Mono-Uruavan

Piva/Bannoni

Choiseul

New Georgia/Isabel — Isabel — Zabana

New Georgia/Isabel — Isabel — central subgroup

New Georgia/Isabel — New Georgia any subject

any subject

any subject

subjects of negative propositions

subjects affected by the event

any subject

unaccusative and experiencer subjects 


\section{B. Palmer}

\section{Distribution and function of possessor-indexing hosts in PVSI}

Both "consumed" and general possessor-indexing hosts participate in PVSI across NWS. This raises several questions: what functional distinction is encoded by host choice in languages which display both in verbal constructions; can the use of both be reconstructed for the originating construction in PNWS; and if reconstructable, how could the nominal functional distinction encoded by these hosts have been meaningfully reanalyzed in a verbal context? This section surveys host choice in synchronic verbal constructions.

\subsection{Distribution of reflexes of PNWS possessor-indexing hosts in PVSI}

PVSI does not occur in Nehan, and no reflexes of PNWS possessor-indexing hosts occur in PVSI in either the Hanahan or Selau dialects of Halia (NNB Buka group). Six languages investigated display reflexes of only one PNWS possessor-indexing host in PVSI. PVSI reflexes of only *na- occur in Hakö and Petats (NNB Buka group); Teop (NNB Saposa-Tinputz group); and Ririo (Choiseul), and of only *ze- in Bannoni (Piva/Bannoni). Reflexes of both the "consumed" and general PNWS possessor-indexing hosts occur in PVSI in Taiof and Tinputz (NNB Saposa-Tinputz group); Papapana (NNB); and in all investigated languages in the Mono-Uruavan and New Georgia/Isabel subgroups. Reflexes of PNWS *na- (either alone or alongside reflexes of * ${ }^{2} e-$ ) therefore occur in PVSI in every first-order subgroup of NWS except Piva/ Bannoni, and PVSI reflexes of PNWS * ${ }^{2}$ - (either alone or alongside reflexes of *na-) occur in every NWS first-order subgroup except Choiseul. Both can therefore be securely reconstructed as present in the originating PNWS construction.

\subsection{Function of host choice in synchronic PVSI in languages where both hosts participate}

Languages displaying reflexes of both PNWS possessor-indexing hosts in PVSI employ this formal distinction to encode a range of functional distinctions.

5.2.1. Host choice in NNB - Saposa-Tinputz group - Taiof. For Taiof PVSI, Ross (2002b: 433) analyzes the general host no- ro- as encoding imperfective aspect, with the "consumed" host $e$ - occurring in "perfective/stative" clauses. As discussed in Section 4.3, Taiof PVSI encodes continuous aspect. PVSI with no- ro- occurs with verbs of all kinds, including stative verbs (see 
[22c] and [22d]), suggesting that that the consumed host is not associated with stative verbs. All examples involving $e$ - in the data express continuous resultative states, suggesting that this host encodes resultative aspectual semantics.

(47) Taiof

a. $u$ buc to taborei $=\boldsymbol{e}-\boldsymbol{n}$

ART canoe REAL be.broken=RSLT-3SG.SBJ

'The canoe is broken.'

(Ross 2002b: 433)

b. aje to $m a t=\boldsymbol{e}-\boldsymbol{n}$

he REAL die=RSLT-3SG.SBJ

'He is dead.'

(Ross 1982: 27)

5.2.2. Host choice in NNB - Saposa-Tinputz group - Tinputz. For Tinputz PVSI Ross (1982: 28) claims that no- "is used in realis contexts", as in (48), while $e$ - "has been found only in conditional clauses", as in (49). In (49) $e$ - marks the main clause, not the conditional clause. The data is consistent with no- marking actual events, and $e$ - hypothetical events.

(48) Tinputz
a. ejs to ep e kovu [to terte
I REAL see ART woman REAL RD carry
no-n o kovei]
CONT-3SG.SBJ ART basket

'I saw the woman who was carrying the basket.'

(Ross 1982: 29)

b. a te to terte no-n iun

ART man REAL RD be CONT-3SG.SBJ house

'The man is in the house.'

(Ross 1982: 28)

c. eys to en en no-o

I REAL RD eat CONT-1SG.SBJ ART some taro

varu amani

now just

'I am eating taro right now.'

(Ross n.d.)

(49) Tinputz

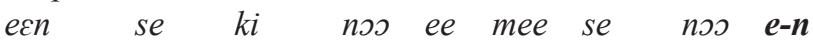 youSG FUT CND go he too FUT go CONT-3SG.SBJ 'If you went, he would go too.'
(Ross 1982: 28) 


\section{B. Palmer}

5.2.3. Host choice in $N N B$ - Papapana. Papapana displays a single paradigm of PVSI. However, this paradigm contains reflexes of both the "consumed" and general hosts. Some person/number categories display no reflex of either host, as with the 1EXCPL subject-indexing form =mani in (37a). However, the 3SG subject-indexing =ena in (37b) reflects the PNWS 3SG indexed "consumed" host * flects the PNWS 2SG indexed general host *na-mu.

5.2.4. Host choice in Mono-Uruavan - Mono. In Mono the general host occurs in PVSI with agentive subjects of both transitive and unergative intransitive verbs, as in (25b) and (40) above. It also occurs with psych and existential verbs and verbs of perception, as in (41), and postural verbs, as in (3a). The $e$ - host is confined to occurring with unaccusative verbs expressing a change of state beyond the control of the subject, as in (3b). The semantic distinction therefore appears to be between events or states that are potentially controllable, and those which the subject undergoes and are beyond their control.

5.2.5. Host choice in Mono-Uruavan - Torau. PVSI host choice in Torau is determined by a complex network of factors involving the interplay of reduplication, tense marking, and the aspectual semantics of the verbs (Palmer 2007a). In a nutshell, a reflex of the "consumed" host occur in clauses that are marked both in modality or tense and in subtype of imperfective, where markedness of imperfective subtype is expressed by reduplication. A reflex of the Proto Mono-Uruavan general host $s a$ - occurs in clauses that are unmarked in modality (i.e., are realis) and tense (i.e., lack overt tense markers), or in subtype of imperfective. Realis is the default modality in Torau, and is not overtly marked unless the realis marker is required to host subject-indexing or past tense marking, while irrealis is always overtly expressed except in imperatives. Clauses that are marked for modality/tense are either irrealis or display overt past or present tense marking.

PVSI occurs encoding various subtypes of imperfective, including stative continuous, progressive, persistive, progressive inchoative or inceptive, and habitual. Most of these subtypes involve reduplication. However, for stative verbs (including experiencer, existential and postural verbs) simple stative continuous aspect does not involve reduplication, and is therefore the unmarked imperfective subtype for stative verbs, while with active verbs (including activity, accomplishment, and achievement verbs) persistive aspect does not involve reduplication, and is therefore the unmarked imperfective subtype for active verbs.

The PVSI host $e$ - occurs in clauses that are marked in terms of both modality/ tense and imperfective subtype. It occurs, therefore, in clauses that are irrealis 
or overtly marked for past or present tense, and express a subtype of imperfective other than simple continuous (for stative verbs) or persistive aspect (for active verbs). The host $s a$ - occurs in all other contexts, in other words, when the clause is realis modality and unmarked for tense (regardless of imperfective subtype), or when the clause is unmarked for imperfective subtype (i.e., lacks reduplication and expresses simple continuous aspect with stative verbs or persistive aspect with active verbs, regardless of modal or tense status).

5.2.6. Host choice in Mono-Uruavan - Uruava. The general host occurs in the limited Uruava data with psych, existential and postural verbs, as in (50a) to (50c). The "consumed" host occurs with agentive verbs, as in (50d) and (50e), and unaccusative verbs, as in (50f). The distinction appears to have been between dynamic events (with $e^{-}$) and static events (with no-).

(50) Uruava

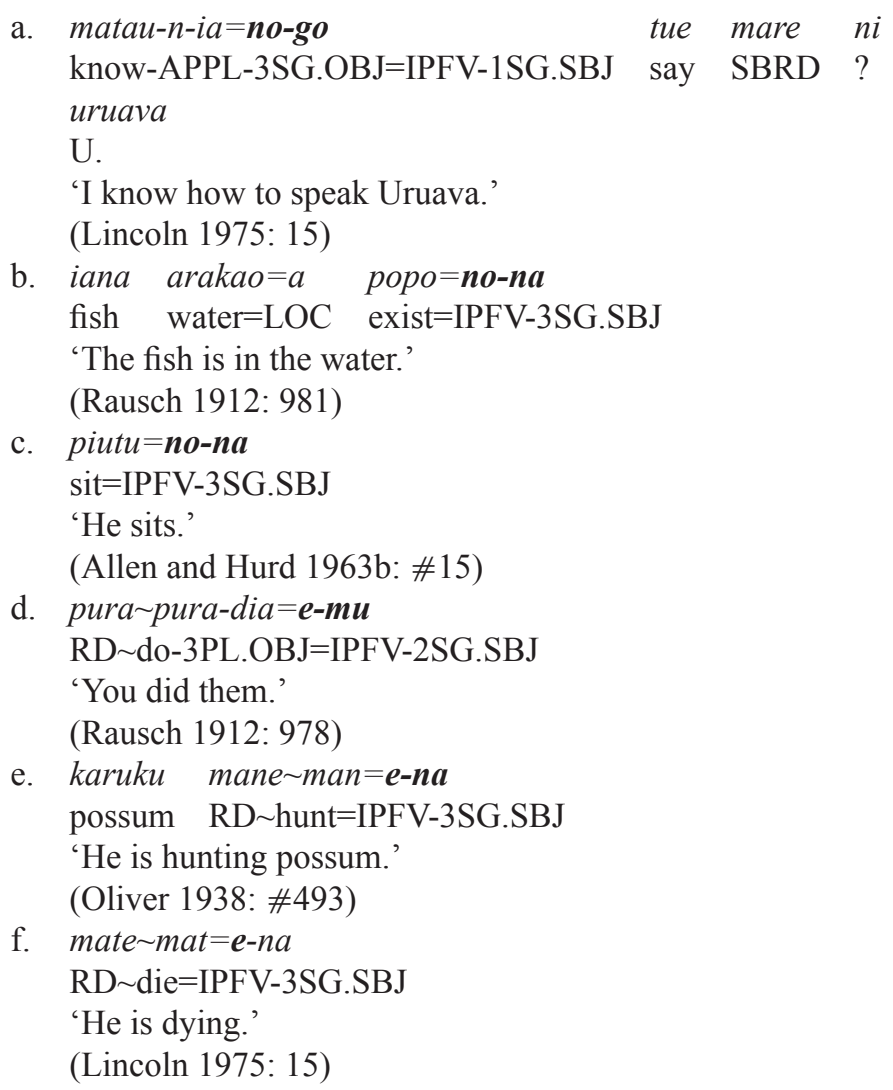




\section{B. Palmer}

5.2.7. Host choice in Santa Isabel - Zabana. Both the general and "consumed" hosts occur in Zabana PVSI, but the general host no- occurs infrequently and appears to be losing ground in a functional broadening of ye-. The ye- host occurs with subjects which have the semantic roles of patient, theme or experiencer, including existential verbs, verbs expressing psychological or physical states, as in (43a), and verbs expressing events the subject has no control over, as in (51a). These verbs cannot be marked with no-. Conversely, the no- host occurs with subjects of unergative verbs where the subject, while an agent, acts in a way that also affects him or herself. This includes various verbs expressing reflexive events in which the subject acts on himself or herself physically or mentally, such as with studying or learning, as in (43b), or bathing, as in (51b). These verbs cannot be marked with ye-

(51) Zabana

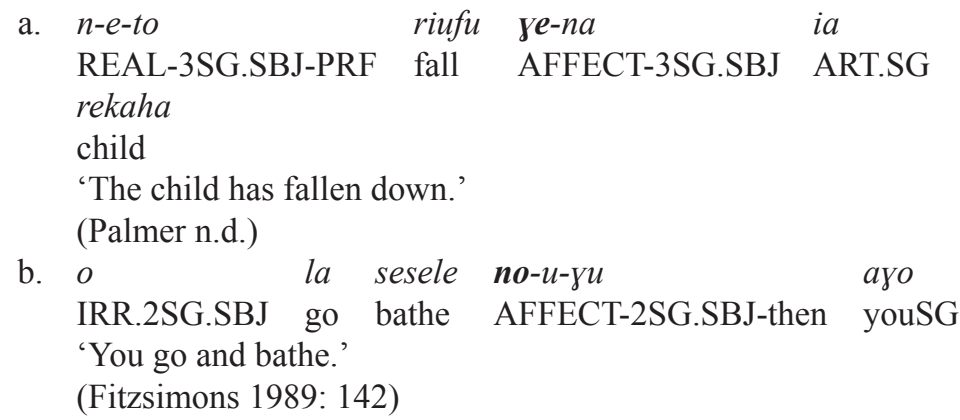

A range of verbs can occur with either no- or ye-, including verbs of motion, verbs of consumption, and verbs where the event affects the subject by changing their location or physical state. However, with these verbs the distinction encoded by host choice is social: the no- forms are reserved for referring to the actions of a high status individual such as a chief or priest. The ye- forms are used to refer to the actions of ordinary members of the community. This presumably functions to emphasize the agency of high status individuals, and underplay that of ordinary individuals. The examples with no- in (52) would be used when referring to or addressing a high status subject and the ye-forms otherwise.

(52) Zabana
a. n-e-to
hinae ye-na/no-na
kia
REAL-3SG.SBJ-PRF descend AFFECT-3SG.SBJ Kia
'He has gone down to Kia.'
(Palmer n.d.)
b. $o$
mahai ye-u/no- $u$
IRR.2SG.SBJ eat
AFFECT-2SG.SBJ 
'Eat please.'

(Fitzsimons 1989: 109; Palmer n.d.)

Informants report that younger speakers rarely use the no- forms with verbs that can take either host, suggesting a weakening of the use of no-. If this continues, and no- is completely lost with verbs that can currently take either, no- would be retained only in examples such as $(51 \mathrm{~b})$, and would acquire the function of indexing reflexive subjects only, while ye- would acquire the function of indexing all nonreflexive affected subjects.

5.2.8. Host choice in Santa Isabel - Cheke Holo. In Cheke Holo the "consumed" host has a reduced distribution in PVSI. White et al. (1988: xx) claim that with $y e$ - the "[i]nvolvement of the subject is intensified further". However, the data suggests that $y e$ - is limited to occurring with verbs expressing events in which the subject is physically affected by the event:

(53) Cheke Holo

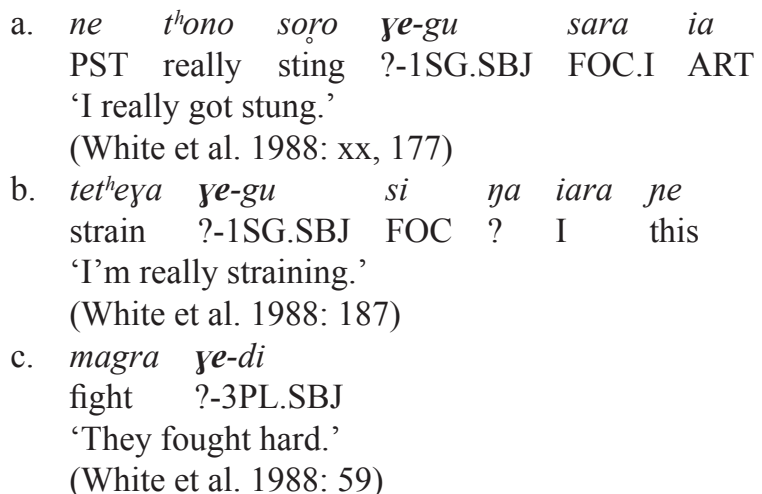

Verbs of all other semantic types are marked with the no- forms, including stative verbs, psych verbs (as in [54a]) and dynamic verbs that do not result in a physical effect on the subject (as in [54b]), including, unlike Zabana, verbs where the subject changes location, as (30b) and (54c) show.

(54) Cheke Holo

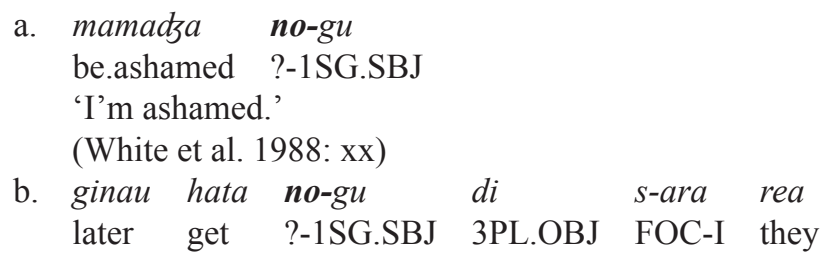


'I will get them later.'

(White et al. 1988: xxxiv)

c. age no-da $k a$ thoyno no

go ?-1INC.SBJ LOC ocean there

'Let's go to the ocean.'

(White et al. 1988: xx)

5.2.9. Host choice in Santa Isabel - Kokota. Both the general host no- and the "consumed" host $y e$ - occur with PVSI in Kokota. However, the distribution of the "consumed" host is highly restricted, occurring only with verbs of consumption:

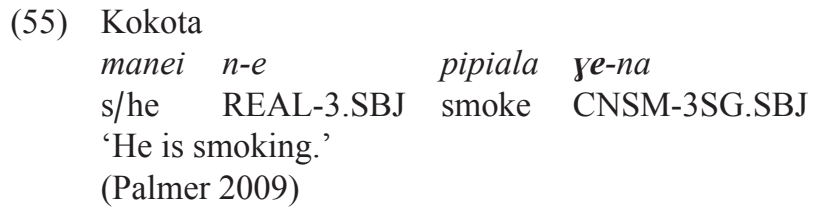

5.2.10. Host choice in New Georgia - Kubokota. In Kubokota PVSI, the "consumed" host ye- occurs infrequently. The functional distinction expressed by the use of $y e$-is not entirely clear. According to Chambers (2009: 142), it occurs with "undergoer subjects, who are more affected by and have less control over the event expressed by the verb." She cites it occurring with verbs meaning 'sleep', 'be hungry', 'fall' and 'be naked'. However, the subject of lotu 'fall' could not be construed as more affected than the subject of uke 'die', which occurs with the general possessive form. The issue of control is no more promising. While it could be argued that sleep and hunger are beyond the subject's control and that the subject of even dying may have control over the circumstances of their life that may bring this about, the same could be said to apply to falling down or being naked. Moreover, inanimate subjects, typically treated as noncontrolling where such a distinction exists, occur in Kubokota with both hosts - as shown with the "consumed" host in (56c) and the general host in (46a) and (46d). The functional distinction expressed by reflexes of the two hosts remains to be determined.

(56) Kubokota
a. rami
burana yemami
REAL.1EXC.SBJ be.hungry 1EXC.SBJ
'We're hungry.'
(Chambers 2009: 142)
b. ...ти lotи уети
REAL.2.SBJ fall 2SG.SBJ


'. . you'll fall down.'

(Chambers 2009: 142)

\begin{tabular}{|c|c|c|c|c|}
\hline$z a$ & tuara & $m i$ & layere & yana \\
\hline $\begin{array}{l}\text { REAL.3SG.SBJ } \\
\text { 'It [a boat] is spe }\end{array}$ & $\begin{array}{l}\text { be.strong } \\
\text { ding down }\end{array}$ & IRR.3SG.SBJ & descend & 3SG.SBJ \\
\hline
\end{tabular}

(Chambers 2009: 142)

5.2.11. Host choice in New Georgia - central subgroup. In both Roviana and Hoava, the "consumed" host ye- occurs extremely infrequently in PVSI, as in Kubokota. Unlike Kubokota, in Roviana and Hoava this corresponds to more restricted use of the 'consumed' host in nominal possession as well (particularly in Roviana where the "consumed" host is almost completely absent from nominal constructions). With PVSI, the general forms occur with postural, motion and existential verbs, as well as indexing experiencer and passive subjects:

(57) Hoava
a. tahiko busa gua
be.afraid too.much 1 SG.SBJ
'I was too afraid.'
(Davis 2003: 173)
b. ta-yani-ni-a gua sa masala heni-ni
PASS-eat-APPL-3SG.OBJ 1SG.SBJ ART criminal this-RD
'I am injured by this criminal.'
(Davis 2003: 173)

In Hoava, the "consumed" host occurs in verbal constructions "occasionally". (Davis 2003: 177) Davis identifies no functional distinction. In the data it is confined to predicates encoding change of location:
(58) Hoava

$\begin{array}{llllll}\text { yore } & \text { ye-di na } & \text { la pota nikana yua } \\ \text { descend } & \text { CONT-3PL.SBJ because } & \text { go hit man }\end{array}$
'They went down to kill people.'
(Davis 2003: 177)

In Roviana, the "consumed" host occurs in verbal constructions so rarely that only two instances are attested: one expressing a change in location, the other meaning 'sleep':
(59) Roviana
a. ...meke and
vura-mae
ye-na
si
keke noki appear-come
CONT-3SG.SBJ ABS one snake


pa kenu-na

LOC front-3SG.PSSR

'. . . and suddenly a snake appeared in front of him.'

(Ross 1988: 250)

b. puta ye-mi

sleep CONT-2PL.SBJ

'You sleep.'

(Waterhouse 1949)

5.2.12. Summary of synchronic function of "consumed" and general hosts in verbal constructions. The findings above are summarized in Table 6.

The pattern that emerges from Table 6 relates to issues of affect and control. In several languages, one host has expanded its functional territory in PVSI, completely supplanting the other. However, where both occur, a reflex of the "consumed" host tends to occur in clauses encoding events in which the subject is affected in some way, or over which the subject has no control, or is restricted to a particular kind of affect or lack of control, while a reflex of the general host tends to occur in clauses encoding events the subject controls or actively participates in.

An exception to this pattern is the recently extinct Uruava, where the data shows the opposite distribution to that predicted by the general pattern. However, Uruava is aberrant in a range of ways, including in the function of possessor-indexing hosts in nominal constructions. Instead of marking general versus "consumed" possession as elsewhere in NWS, no- marks plural possessums and $e$ - singular possessums:

(60) Uruava
a. $\boldsymbol{e}-g u$
avutei
SG.PSSM-1SG.PSSR brother-in-law
'my brother-in-law'
(Rausch 1912)
b. no-gu
avu avutei
PL.PSSM-1SG.PSSR RD brother-in-law
'my brothers-in-law'
(Rausch 1912)

\begin{abstract}
Aberrant Uruava phenomena such as this may simply be artifacts of inadequate or limited description, or rememberer phenomena in a moribund language, although materials from differing sources and times are consistent in their aberrant features. Alternatively, they may result from Papuan contact. Whatever the reason, the overall aberrant nature of Uruava patterns diminishes the significance of this counterexample to the general functional pattern.
\end{abstract}


Table 6. Function of general and "consumed" hosts in synchronic PVSI

\begin{tabular}{|c|c|c|c|c|}
\hline & & & general host & consumed host \\
\hline \multirow{7}{*}{$\begin{array}{l}\text { Nehan/North } \\
\text { Bougainville }\end{array}$} & \multicolumn{2}{|l|}{ Nehan } & - & - \\
\hline & \multirow[b]{2}{*}{ Buka } & Petats, Hakö & present continuous events & - \\
\hline & & $\begin{array}{l}\text { Hanahan, } \\
\text { Selau }\end{array}$ & - & - \\
\hline & \multicolumn{2}{|c|}{ Papapana } & part of single paradigm & part of single paradigm \\
\hline & \multirow{3}{*}{$\begin{array}{l}\text { Saposa/ } \\
\text { Tinputz }\end{array}$} & Taiof & $\begin{array}{l}\text { dynamic and most stative } \\
\text { events }\end{array}$ & resultative states \\
\hline & & Teop & all contexts & - \\
\hline & & Tinputz & ?real events & ?hypothetical events \\
\hline \multicolumn{3}{|l|}{ Piva/Bannoni } & - & $\begin{array}{l}\text { permissive/prohibitive } \\
\text { clauses }\end{array}$ \\
\hline \multicolumn{3}{|l|}{ Choiseul } & all contexts & - \\
\hline \multirow{3}{*}{$\begin{array}{l}\text { Mono- } \\
\text { Uruavan }\end{array}$} & \multicolumn{2}{|l|}{ Mono } & controllable states/events & $\begin{array}{l}\text { uncontrollable states/ } \\
\text { events }\end{array}$ \\
\hline & \multicolumn{2}{|l|}{ Torau } & $\begin{array}{l}\text { simple realis or simple } \\
\text { continuous/persistive } \\
\text { events }\end{array}$ & $\begin{array}{l}\text { irrealis or past or present } \\
\text { tense and marked } \\
\text { imperfective subtype }\end{array}$ \\
\hline & \multicolumn{2}{|l|}{ Uruava } & states & $\begin{array}{l}\text { dynamic and punctual } \\
\text { events }\end{array}$ \\
\hline \multirow{6}{*}{$\begin{array}{l}\text { New } \\
\text { Georgia/ } \\
\text { Isabel }\end{array}$} & \multirow{3}{*}{ Isabel } & Zabana & "reflexive" acts & most contexts \\
\hline & & Cheke Holo & most contexts & $\begin{array}{l}\text { events affecting subject } \\
\text { physically }\end{array}$ \\
\hline & & Kokota & most contexts & events of consumption \\
\hline & \multirow{3}{*}{$\begin{array}{l}\text { New } \\
\text { Georgia }\end{array}$} & Kubokota & most contexts & $?$ \\
\hline & & Hoava & most contexts & change in location \\
\hline & & Roviana & most contexts & change in location; sleep \\
\hline
\end{tabular}




\subsection{Diachronic development of host choice in PVSI}

The findings so far support hypotheses about the diachronic development of host distribution in PVSI. In NNB, both hosts were retained in PVSI at the level of Proto-NNB. The construction was subsequently lost (or never occurred) in Nehan. In Papapana, a host-based functional distinction was lost and the two hosts were absorbed into a single collapsed paradigm. In the Buka group, the "consumed" host was completely lost from PVSI, while the general host also atrophied functionally, being completely lost in Halia, while becoming functionally dissociated with the subject-indexing and undergoing functional narrowing to encode present continuous aspect in Petats and Hakö. In the Saposa/Tinputz group, the "consumed" host again underwent functional narrowing, being lost completely in Teop, while acquiring narrower functions of encoding only resultative states and hypothetical events respectively in Taiof and Tinputz.

In Choiseul, the "consumed" host was lost in PVSI. In Piva/Bannoni the general host was lost in PVSI, and the consumed host underwent a functional narrowing to index only the subjects of permissive or prohibitive constructions. In Mono-Uruavan, both hosts were retained, developing divergent functional characteristics in the three languages.

In New Georgia both hosts were retained, but the "consumed" host has undergone functional narrowing to events in which the subject sleeps or is an experiencer, and may be in the process of being lost altogether from PVSI. The same is true of the central Santa Isabel group, which has retained both hosts but may be losing the "consumed" host, with clear functional narrowing for that host. In Zabana, the reverse is the case. The general host developed the social function of marking respect, and appears to be losing ground in all contexts except clearly reflexive events.

\section{Diachronic development of NWS PVSI}

\subsection{Originating construction}

PVSI morphology reflecting earlier possessive morphology is found in all firstorder subgroups of NWS. The synchronic phenomenon therefore originated in a construction at the level of PNWS in which a participant in an event was treated as a possessor. Given that the original pre-NWS function of the relevant morphology was nominal possessor-indexing, and the verbal subject-indexing function is a later development confined to NWS, this originating construction must have been nominal. However, given that the originating construction was 
reanalyzable as a verbal construction, it must have involved a verb or verbal construction, or a form interpretable as a verb. The originating construction is therefore assumed by Ross (1982) to have been a nominalization. A number of questions remain to be answered about the nature and status of this nominalization, and how its attendant possessive morphology came to be reanalyzed with a verbal function.

\subsection{Nominalized verb or nominalized clause?}

Ross (1982: 38-41) proposes a diachronic path leading to the development of NWS PVSI involving three stages: the originating construction was a nominalized verb, which then attracted overt arguments, becoming a nominalized clause, and was then in turn reanalyzed as a verbal main clause. The crucial question relating to Ross's hypothesis is whether the initial stage was a nominalized verb, as he proposes, or a nominalized clause.

Ross's hypothesis depends heavily on synchronic evidence from Mono, which he argues retains construction types representing each of the three diachronic stages. Given the crucial nature of synchronic Mono to Ross's proposed diachronic path, and therefore to the claim that synchronic PVSI developed out of a nominalized verb construction, this hypothesis is tested against a more fine-grained investigation of the Mono data.

6.2.1. Ross's hypothesis. Ross (1982: 38-41) proposes that NWS PVSI developed in three stages, each involving a distinct morphosyntactic construction with distinct discourse-functional characteristics. The formal and functional characteristics of each of Ross's stages may be summarized as follows:

\begin{tabular}{|c|l|l|}
\hline Stage & Structural characteristics & Functional characteristics \\
\hline \multirow{2}{*}{1} & A nominalized nonfinite verb: & "[P]revious action is \\
& - lacking tense, aspect or & briefly recapitulated . . to \\
& modal marking, subject- & provide a temporal \\
& indexing, a preverbal topic & (sequential) setting for the \\
& or overt argument NPs; & following clause." (Ross \\
& - possessor-indexed to one & 1982: 38) The nominalized \\
& of the participants in the & verb functions as a \\
& referent event; & "thematic topic" (Olsen \\
& - sentence initial but & 1979) of the main clause. \\
& "syntactically independent" & New information may not \\
& of the following clause. & be introduced. \\
\hline
\end{tabular}




\begin{tabular}{|c|l|l|}
\hline 2 & $\begin{array}{l}\text { A nominalized finite clause: } \\
- \text { displaying standard } \\
\text { subject-indexing and tense, } \\
\text { aspect and mood marking; } \\
-\begin{array}{l}\text { allowing postverbal } \\
\text { argument NPs; } \\
- \text { still not allowing a } \\
\text { preverbal topic; } \\
\text { - still sentence initial and } \\
\text { "syntactically } \\
\text { independent". }\end{array}\end{array}$ & $\begin{array}{l}\text { A "[s]ubordinate clause of } \\
\text { time" providing a temporal } \\
\text { setting for the following } \\
\text { clause (still a "thematic } \\
\text { topic"). But "does not } \\
\text { directly recapitulate a } \\
\text { previous verb". (Ross } \\
1982: 39)\end{array}$ \\
\hline 3 & $\begin{array}{l}\text { An independent finite verbal } \\
\text { clause: } \\
- \text { allowing a preverbal topic; } \\
\text { no longer forming a single } \\
\text { sentence with a following } \\
\text { clause. }\end{array}$ & $\begin{array}{l}\text { An independent main } \\
\text { clause not relatable to a } \\
\text { following clause, } \\
\text { expressing habitual action. } \\
\text { (Ross 1982: 40) }\end{array}$ \\
\hline
\end{tabular}

The morphosyntactic factors which Ross uses to distinguish the three stages are therefore:

(62) a. whether or not the structure is a nominalization;

b. whether or not the structure is sentence initial;

c. the presence or absence of preverbal subject agreement;

d. the presence or absence of preverbal tense/modal marking;

e. the permissibility of overt nontopic argument NPs;

f. the permissibility of a preverbal topic;

The functional characteristics of each stage can be characterized on the basis of two factors:

$\begin{array}{ccc}\text { (63) Stage } & \text { Recapitulative } & \text { Temporal setting for the following clause } \\ 1 & \sqrt{ } & \sqrt{ } \\ 2 & \mathrm{X} & \sqrt{ } \\ 3 & \mathrm{X} & \mathrm{X}\end{array}$

Ross proposes that subsequent developments took place within daughter branches, but that each functional/structural type corresponding to the three stages of development are preserved in synchronic Mono (Ross 1982: 37-38). Stage 1 is shown in (64), stage 2 in (65) and (66), and stage 3 in (67). In each example here the PVSI clause is enclosed in square brackets. 
(64) Mono

1. $r-e=h o s e$

3PL.SBJ-REAL=paddle

'They paddled.'

2.-3. [ho hose sa-ria

$\varnothing$ - $i=k a p a \quad g a$

$\mathrm{RD} \sim$ paddle IPFV-3PL.SBJ $3 \mathrm{SG} . \mathrm{SBJ}-\mathrm{REAL}=$ fall ABS

pakusi

axe

'[While] they were paddling, the axe fell (into the water).'

(Ross 1982: 38)

(65) Mono

1. sa-na bataha dimoai $\varnothing-i=m e k a-s o h a$

GENP-3SG.PSSR woman Dimoai 3SG.SBJ-REAL=long-wait

'Dimoai's wife waited a long time.'

2. $\varnothing$ - $i=$ taoho

3SG.SBJ-REAL=mourn

'She mourned.'

3.-5. [roro sa-na $] \quad$ [roro sa-na $]$

see IPFV-3PL.SBJ see IPFV-3PL.SBJ

$\varnothing-i=b o i$

3SG.SBJ-REAL=night

'As she kept looking for him, night fell.'

(Ross 1982: 39)

(66) Mono
1.-2. $\quad[\boldsymbol{o}-\boldsymbol{n}=a u \quad \boldsymbol{s a}-\boldsymbol{m}]$
2SG.SBJ-REAL=exist IPFV-2SG.SBJ
ha-na=nuhu-i-Ø

1SG.SBJ-IRR=dive-TR-3SG.OBJ

'While you stay here, I shall dive for it.'

(Ross 1982: 15)

(67) Mono

[boitalu hanua-ay alu roro- $i-a$

formerly people-LOC PNLOC see-TR-3SG.OBJ

sa-ria ga niunu]

IPFV-3PL.SBJ ABS coconut

'Formerly, the Alu people could see the coconut palm.'

(Ross 1982: 40)

6.2.2. Reexamining Ross's three proposed stages in Mono. A detailed examination of the Mono text corpus (Wheeler 1926) does not support the notion of three distinct synchronic clause structures. Each morphosyntactic factor in (62) is investigated separately. 
6.2.2.1. Nominalization. Ross argues that Stages 1 and 2 are nominalizations, while Stage 3 is an independent verbal clause. However, it is not clear what defines Stages 1 and 2 as nominalizations. No dedicated nominalizing morphology occurs in Mono. The apparent possessive morphology occurs in all three stages, so that it alone cannot distinguish nominalizations from nonnominalized verbal clauses. The status of Stages 1 and 2 as nominalizations appears to be an inference based on other proposed morphosyntactic restrictions such as sentence initial position and the absence of preverbal topics. There is therefore no evidence in the data relating to nominalization that constitutes evidence of distinct stages.

6.2.2.2. Sentence initial status. Ross claims Stage 1 and 2 clause types are "sentence initial", but "syntactically independent", presumably meaning that they form a single intonational unit with the following clause, but lack overt markers linking the two clauses. Ross presents no evidence placing both clauses in a single sentence. However, even assuming clauses in Stages 1 and 2 do form a single intonational sentence with the following clause, this is not evidence that they constitute distinct clause types, because in Mono, sequences of Stage 3 independent main clauses may be conjoined and display a single sentence intonation pattern without overt conjunction.

6.2.2.3. Preverbal subject agreement and TAM. Ross argues that preverbal subject-indexing and TAM marking does not occur in Stage 1, but does occur in Stage 2 and Stage 3. However, the Mono data shows occasional preverbal subject agreement and modal marking in clauses with the recapitulative contextualizing function characteristic of Stage 1:

(68) Mono

1. kirikoputu e-na=guhe peta-ay

Kirikoputu 3SG.SBJ-IRR=roll ground-LOC

'Kirikoputu rolls along the ground.'

2. [e-na=gu guhe-titi sa-na peta-ay $]$

3SG.SBJ-IRR=RD roll-ITER IPFV-3SG.SBJ ground-LOC

poa reapa, uli-na e-na=honu peta

path long body-3SG.PSSR 3SG.SBJ-IRR=be.full ground

'She goes rolling and rolling along the ground, the path is long,

[and] her body gets covered with mud.'

(Wheeler 1926: text 1)

6.2.2.4. Permissibility of overt nontopic arguments. Ross argues that overt nontopic argument NPs occur in Stages 2 and 3, but not in Stage 1 recapitulative clauses. However, the data provides evidence of clauses with Stage 1 func- 
tions displaying overt arguments. In (68), clause 2 has a postverbal oblique. In (69), clause 2 resembles the recapitulative function in (64) clause 2 , but has a postverbal subject:

(69) Mono

1. $\quad$ ir $-i=$ simo

3PL.SBJ-REAL=play.pipes

'They [Big Pakomani and his men] danced and sang and played the pipes.'

2. [si simo sa-ria ga pakomani kanega-na RD play.pipes IPFV-3PL.SBJ ABS Pakomani big-3SG.PSSR sa-na talaua]

GENP-3SG.PSSR people

'Big Pakomani and his men went on making music and dance, [and]'

3. pakomani kairiki-na $\quad$-i=safili

Pakomani small-3SG.PSSR 3SG.SBJ-REAL=emerge hither

'Little Pakomani came forth.'

(Wheeler 1926: text 49)

In (70), clause 6 recapitulates and provides temporal context but has a preverbal nontopic subject:

(70) Mono

1.-2. "iahaua ga $\varnothing-i=u e^{\prime \prime}$

why TOP 3SG.SBJ-REAL=disappear

$\varnothing-i=u a \quad$ ga nitu

3SG.SBJ-REAL=say ABS spirit

" "Why is he running away?" said the spirit.'

3.-4. Ø-i=toka Ø-i=tatagu

3SG.SBJ-REAL $=$ chase 3 SG.SBJ-REAL $=$ run

'He went after him. He ran.'

5. ea mea ir $-i=$ polo- $i-\varnothing \quad$ ena loe

DEM pit 3SG.SBJ-REAL=cover-TR-3SG.OBJ INSTR leaf

'They [the villagers] covered up the hole with leaves.'

6. $\quad[$ ea nitu ta tatagu sa-na $]$

DEM spirit RD run IPFV-3SG.SBJ

'The spirit went on running, [and]

7. $\varnothing-i=s o k u$

famata- $\eta$

3SG.SBJ-REAL=arrive village-LOC

he reached the village.'

(Wheeler 1926: text 6) 
Like other NWS languages, Mono makes extensive use of pro-drop. Clauses of all types lack overt arguments unless a mention is required for referent tracking or pragmatic functional purposes. Recapitulative clauses typically require no overt mentions because their recapitulative nature allows unambiguous identification of argument antecedents. However, recapitulative clauses can have overt arguments if required, as in (68) to (70). Conversely, independent main clauses without PVSI typically lack overt arguments in the same discourse contexts, as in (71). The strong tendency for recapitulative clauses to lack overt NPs therefore relates to discourse tendencies, rather than syntactic possibility.

(71) Mono

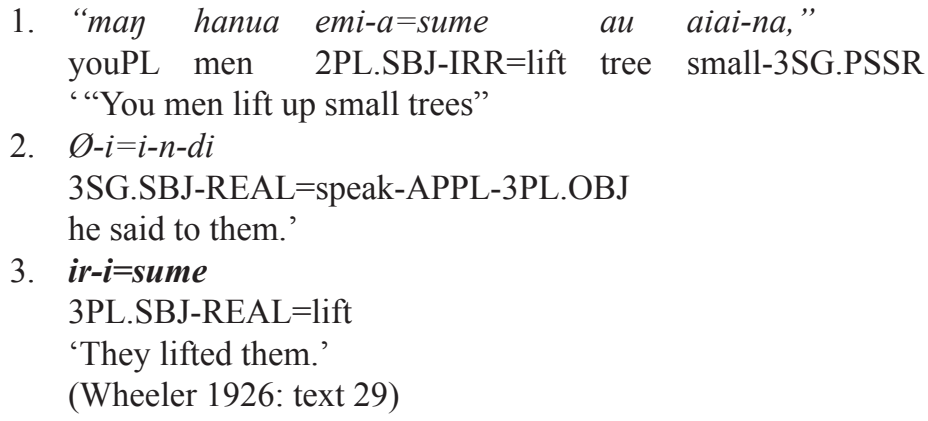

6.2.2.5. Permissibility of preverbal topics. Ross argues that preverbal topics occur in clauses with postverbal subject agreement in Stage 3, but not in Stages 1 or 2 . However, the Mono data shows Stage 2 clauses with a preverbal topic. Clause 1 in (72) corresponds directly to the Stage 2 clause in (66) clause 1 , providing the temporal setting for the following clause, but has a preverbal topic:

(72) Mono

1. [maha ga ha-na=areai sa-gu

I TOP 2SG.SBJ-IRR=speak IPFV-2SG.SBJ

'[While] I will go on speaking,

2. maito $o-n a=u e$

youSG 2SG.SBJ-IRR=disappear

you will escape.'

(Wheeler 1926: text 18)

The Mono data also shows Stage 1 clauses with preverbal topics. In (73), clause 3 has a recapitulative function and sets the scene for the subsequent clause, but has a preverbal topic NP. As with nontopic NPs, the tendency for contextualizing clauses, recapitulative or otherwise, to lack preverbal topics relates to discourse tendencies, not syntactic permissibility. 
(73) Mono

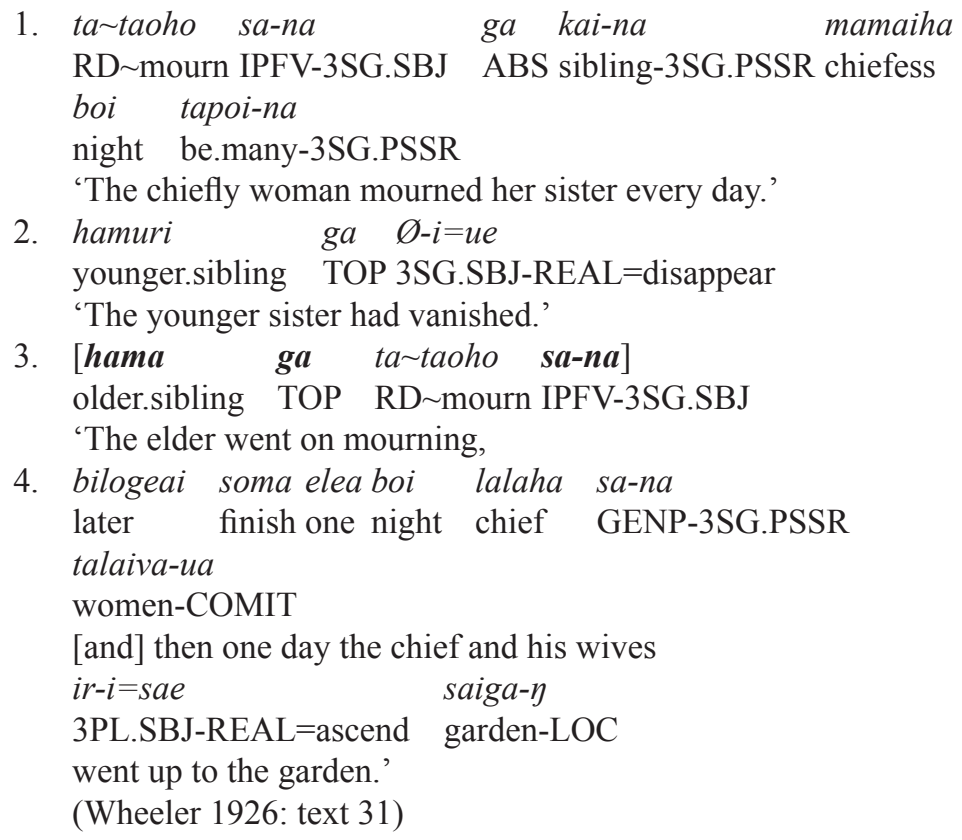

6.2.2.6. Summary of Mono findings. Synchronic Mono does not display three distinct formal and functional constructions supporting the three stages of development proposed by Ross (1982) for PVSI, and does not provide evidence that synchronic PVSI developed out of verb nominalization, rather than nominalized clauses.

6.2.3. Clause-initial recapitulative nominalizations in NWS languages with overt nominalizing morphology. Mono lacks an overt nominalizing form, so there are no morphological grounds for recognizing a nominalized verb. However, several NWS languages do display a nominalizing infix $<$ in $>$ (members of the New Georgia subgroup) or prefix ni- (Nehan) that is cognate with forms outside NWS and is reconstructable for PNWS. In such languages, the nominalizing morphology derives nominalized verbs, as in (74a), but does not occur with nominalized clauses. It therefore allows a clear distinction to be observed between nominalized verbs and nominalized clauses. In these languages, recapitulative structures involving Ross's Stage 1 corresponding to those in Mono exemplified by (64) above do not display the nominalizing morphology, as in (74b), demonstrating that they represent nominalized clauses, not nominalized verbs. 
(74) Roviana

a. <in>ene

$<$ NMLZ $>$ walk

'journey'

(Waterhouse 1949: 228]

b. me [ene la gua dia] tutuv-i-a

and walk go be.like PSSR.3PL.PSSR meet-TR-3SG.OBJ

ri se boko

they ABS Pig

'And [as] they were walking along, they met Pig.'

(Corston-Oliver 2002: 479)

\subsection{The originating nominalization}

On the basis of the discussion above, it is proposed that the originating PNWS construction out of which synchronic PVSI developed was a nominalized clause, not a nominalized verb. The originating nominalization would have been possessor-indexed to one of the verb's logical arguments. This raises several further issues:

(75) a. Do synchronic nominalizations support an indirectly possessorindexed nominalization? If yes, what argument would have been indirectly possessor-indexed in an originating nominalization, and would that be consistent with the development of PVSI as subjectindexing?

b. Why is the order of verb plus "possessive" subject-indexing the opposite of the nominal order of possessor-indexed host plus possessum noun?

c. What nominal functional context could have given rise to the presence of both general and "consumed" possessor-indexing hosts in PVSI?

6.3.1. Possessive construction and indexed argument. Given that PVSI in synchronic NWS involves indirect possessor-indexing, or indexing that has developed out of earlier indirect possessor-indexing, the originating construction must have displayed indirect rather than direct possessor-indexing morphology. Any plausible candidate for an originating nominalization must have indirectly possessor-indexed the relevant argument.

Data on the possession of nominalizations across NWS is limited, and absent for many of the languages. However, a pattern does emerge. In the 14 languages for which data is available on the possession of a nominalized tran- 
sitive verb or clause, where the possessor is the logical object, all 14 index that object using the direct construction. Direct possessor-indexing of the logical object is therefore reconstructable for PNWS nominalizations, both nominalized verbs and nominalized clauses.

The permissibility of an indexing strategy used with the possession of a nominalized transitive construction by its logical A is not well attested. For all but two NWS languages there is no data on possessor As. However, data from Duke (Scales n.d.b.) and Kubokota (Chambers 2009: 91-93, n.d.) indicate that in these languages logical A may be possessor, and is indirectly possessorindexed using the general host, both with nominalized verbs, as in (76a), and nominalized clauses, as in (76b).

(76) a. Duke

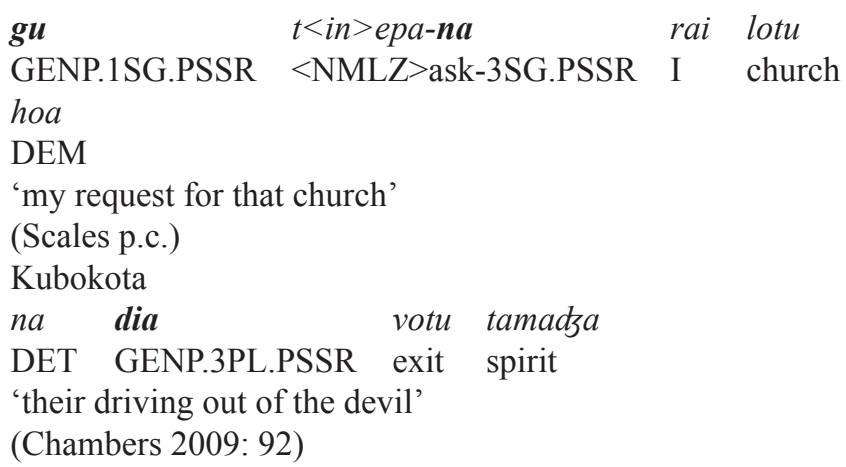

The picture with possessor logical subjects of intransitive nominalizations is less clear. Some NWS languages index logical S possessors indirectly, as in (77). Others do so using the direct construction, as in (78) and (79).

(77) Sisiqa
a. ona
PSSR.3SG.PSSR work
'his work'
(Ross 2002a: 461)
b. ona le
PSSR.3SG.PSSR die
'his death'
(Ross 2002a: 461)

(78) Kubokota
a. na madza=na tabura
ART hit=3SG.PSSR ART Tabura
Tabura's hitting'
(Chambers n.d.) 
b. na uke=na $i \quad$ bil

ART die=3SG.PSSR ART Bill

'Bill's death'

(Chambers n.d.)

(79) Roviana

a. govete taloa-di

flee go.away-3PL.PSSR

'their running away'

(Todd 2000: 85)

b. lodu-na sa rimata

set-3SG.PSSR ART sun

'the sun's setting.'

(Todd 2000: 85)

It is likely, however, that it is the direct indexing of logical S possessors that is the innovation. Indirect possessor-indexing of logical $\mathrm{S}$ is attested in all firstorder subgroups of NWS, while direct possessor-indexing of logical S is only attested in one second-order subgroup (New Georgia). ${ }^{4}$ Moreover, all other Meso-Melanesian languages (the wider grouping within Oceanic containing NWS) where possession of nominalizations is attested index the logical subject of nominalized intransitive verbs and clauses using a general indirect construction. These include Siar and Kuanua (a.k.a. Tolai), both immediate sister languages to NWS, and the slightly more distant Tungak.

(80) a. Siar

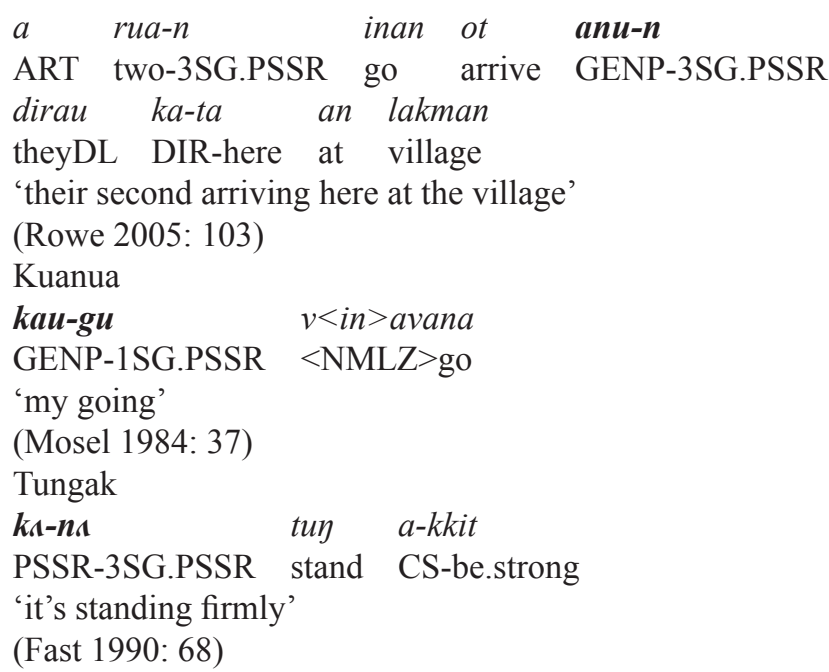

On the basis of this evidence we can posit for PNWS a nominalization construction in which the logical object is directly possessor-indexed, and the 
logical S (and, if permitted as possessor, the logical A) were indirectly possessor-indexed. This is consistent with indirect possessor-indexing of a nominalization as the source of a synchronic subject-indexing construction involving former possessor-indexing morphology.

6.3.2. Preposed possessor-indexing and postposed subject-indexing. The order of verb and subject-indexing seen in PVSI across NWS is consistently verb followed by subject-indexing host. This is the opposite of the standard NWS (and wider Oceanic) nominal possessive order of possessor-indexing host followed by possessum noun. If the originating construction for PVSI was a nominalization, this requires an explanation.

In nominal indirect possessive constructions across NWS, the order of indexed host and possessum noun is HOST $+\mathrm{N}_{\mathrm{PSSM}}$, as in (81), from Nehan (Nehan/North-Bougainville), and (82), from Duke (New Georgia).

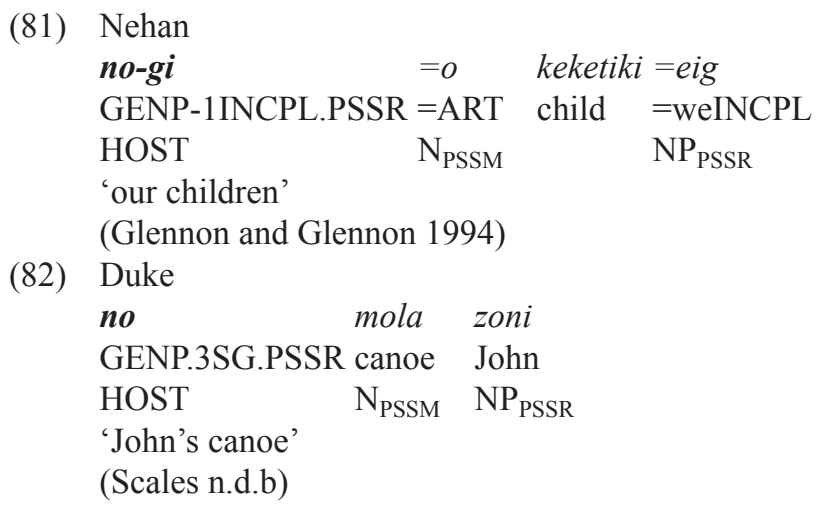

This order is found across NWS, accords with the order found widely in Oceanic, and is reconstructable for PNWS and for Proto Oceanic. (Lichtenberk 1985; Lynch et al. 2002: 77) However, several NWS languages, from Nehan at the northwestern extreme to Duke near the opposite end of the chain, also display the reverse order $\mathrm{NP}_{\mathrm{PSSM}}+\mathrm{HOST}+\left(\mathrm{NP}_{\mathrm{PSSR}}\right)$, as in (83) and (84).

(83) Nehan

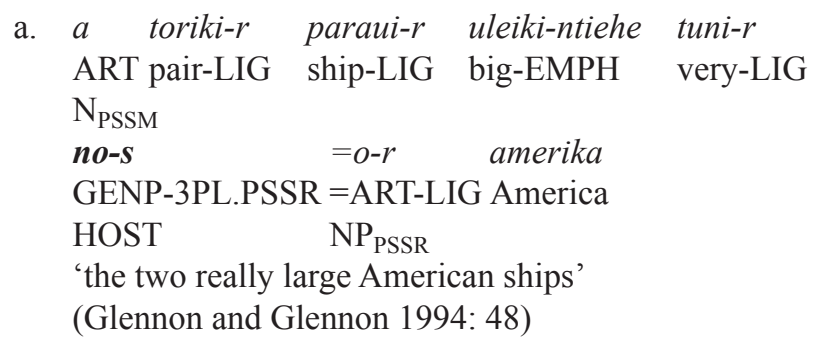




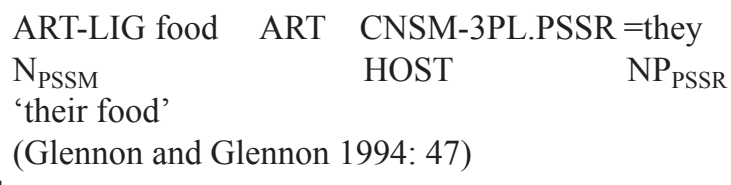

(84) Duke

votusu nona kinavu nakovala

smoke GENP.3SG.PSSR fire Nakovala

$\mathrm{N}_{\text {PSSM }}$ HOST $\mathrm{NP}_{\text {PSSR }}$

'smoke from Nakovala's fire'

(Scales n.d.b.)

The distribution of this alternation across NWS suggests it is reconstructable for PNWS. This is supported by the fact that a similar alternation is found in several closely related languages outside NWS, such as Siar, in (85). Pre-Siar was a sister of PNWS, and the Siar language locus is geographically closest to NWS of any non-NWS language, its closest NWS neighbor being Nehan. It is spoken at the southernmost tip of New Ireland, the obvious departure point for population dispersal east to Nehan-speaking Nissan Island and the Bougainville group beyond.

(85) Siar

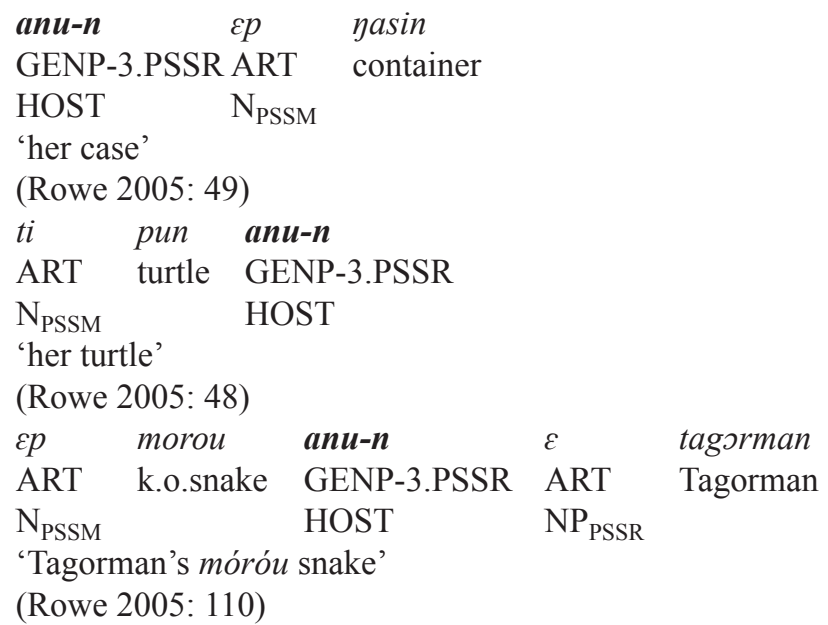

The presence of this alternation in Siar suggests it is reconstructable for Proto South New Ireland/Northwest Solomonic, the immediate ancestor of pre-Siar and PNWS.

The function of the distinction between the two orders in Duke is unknown, as is the function of the alternation between (85a) and (85b) in Siar, although 
in Siar only the $\mathrm{N}_{\text {PSSM }}+$ HOST order is possible if an overt possessor NP is present, as in (85c). In Nehan, the alternation corresponds in part to NP weight. In all attested Nehan examples in which a possessum noun carries modifiers, as in (83a), it precedes the possessor-indexing host, although this is not a requirement, as (83b) shows. It is possible that the construction in (83) is, or at least was historically, a relative clauses construction in which the possessum is expressed as the head noun, and modified by a relative clause with a nominal predicate expressing the possessor. This relative clause possessive predicate parallels the occurrence of possessive predicates in main clauses, as in (86a), and the same is true of Duke ([86b]) (the nominal possessive predicates are bracketed). Relative clauses in Nehan and Duke display no relativizing particle or marker, so nominal possessive predicates in relative clauses are formally indistinguishable from other indirectly possessor-indexed NPs, except for the extraction and gapping of the controlled possessum NP itself.

(86) a. Nehan

a tinih-ene $\quad\left[\begin{array}{ll}a & \text { no-gu}=o\end{array}\right.$

ART canoe-DEM ART GENP-1SG.PSSR=I

'This canoe is mine.'

(Glennon and Glennon 1994: 11)

b. Duke

$\begin{array}{lll}\text { [ya-na } & \text { aia }] & \text { sana } \\ \text { CNSM-3SG.PSSR } & \text { s/he } & \text { DEM }\end{array}$

'That is hers.'

(Scales n.d.a)

Whether or not the construction in (83) and (84) involves a relative clause, given that nominalized clauses are typically heavier than a bare noun, a regime such as that in Nehan would favor postposed possessor-indexing of a nominalized clause, giving an order in which the possessor-indexing subsequently reanalyzed as subject-indexing would occur after the verbal head of the nominalization. This context would give rise the postverbal locus of the resulting subject-indexing seen in NWS PVSI.

On the basis of this, we would expect to find postposed possessor-indexing of nominalizations in Nehan. Unfortunately, the data on the possession of nominalizations in Nehan is very limited. Verbs are nominalized with the prefix $n i-$, and unergative subject possessors are indirectly possessor-indexed using the general host located before the possessum noun, as with underived nouns, as in (87). Unfortunately, the Nehan data includes no examples of the possession of a nominalized clause by its $\mathrm{S}$ or $\mathrm{A}$, so it is not known whether nominalized clauses with indirect possessor-indexing locate the host before or after the verb. 
(87)

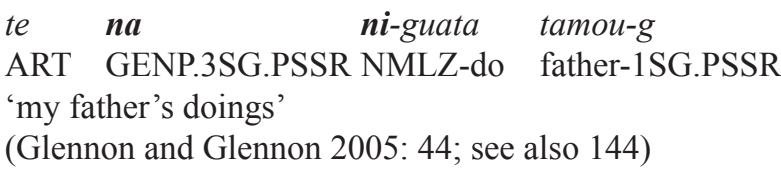

However, traces of the proposed originating nominalization are found elsewhere in NWS. In Babatana (Choiseul), for example, nominal possession always involves the order HOST $+\mathrm{N}_{\mathrm{PSSM}}$, even when the possessum is a nominalized verb (which lack overt nominalizing morphology in Babatana), as in (88). However, nominalized clauses alone always display the opposite order (89). This suggests that the originating construction was a nominalized clause, not a nominalized verb.

(88) Babatan

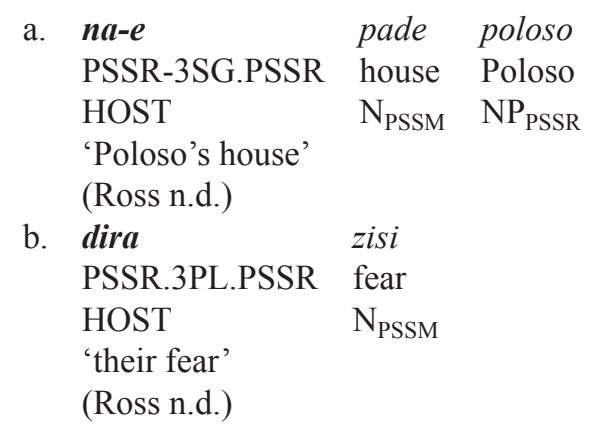

(89) Babatana

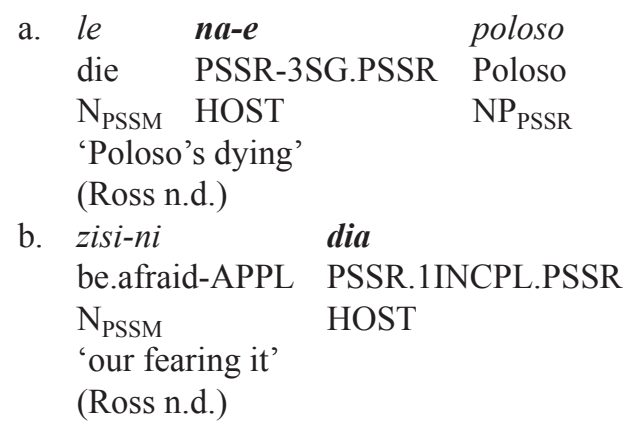

6.3.3. Development of "consumed" and general host functions in verbal constructions. As Table 6 above shows, the "consumed" and general hosts both occur in verbal constructions in languages from every first-order subgroup of NWS except Piva/Bannoni, where only the "consumed" host occurs, although in some individual languages in each subgroup only one host occurs. In 10 of the 20 languages and dialects, both occur, though in some cases the function of one is significantly restricted. In several others only the general host occurs, 
while in Bannoni only the "consumed" host occurs. This distribution suggests that both were present in the originating nominalization.

The semantic distinction encoded by the two hosts in nominal possession is between possessive relations with items consumed, and other general alienable possessive relations. This raises the question of how a nominal distinction like this could be mapped onto the semantics of relationships between events and their participants. The answer lies in semantically noncanonical uses of "consumed" (or "food") possessor-indexing hosts, particularly the phenomenon of passive possession. Passive possession is defined by Palmer (2007b, 2008) as "the distinctive formal treatment of possessum-possessor relations in which: a) he possessum acts on or directly affects the possessor; or b) the possessor has no control over the fact of the relation."

This includes possessive relations with individuals who act against the possessor, and with instruments that are used against the possessor rather than being owned by the possessor, as well as possessums over which the possessor has no control. In a majority of Oceanic languages that mark passive possession, it is marked using a possessor-indexing host otherwise used to mark possession of items eaten (Palmer 2007b, 2008). The best described language in this respect is Standard Fijian, where a "food" possessor-indexing host ${ }^{5}$ is used with characteristics that are inherent and therefore beyond the possessor's control or that are uncontrolled because the possessor is inanimate, or are instruments used on the possessor.

(90) Fijian
a. $\boldsymbol{k e}$-mu $m a^{n} r a i$
FOOD-2SG.PSSR bread
'your bread'
(Lynch 1996: 94)
b. по-mu vale
GENP-2SG.PSSR house
'your house'
(Lynch 1996: 94)
FOOD-2SG.PSSR big
'your size'
c. $\boldsymbol{k e}$-mu levu
(Geraghty 1983: 249)
d. $\boldsymbol{k e - n a}$ yaya
FOOD-3SG.PSSR usefulness
'its usefulness'
(Schütz 1985: 459-460)
e. no-na yaya
GENP-3SG.PSSR usefulness 
'his/her usefulness'

(Schütz 1985: 459-460)

f. $\quad \boldsymbol{k e}$-na wai

FOOD-3SG.PSSR club

'his club (with which he is killed)'

(Palmer 2007b, 2008, forthcoming)

g. no-na wai

GENP-3SG.PSSR club

'his club (which he owns)'

(Palmer 2007b, 2008, forthcoming)

"Food" marked passive possession is also seen in morphologically nominalized verbs in Standard Fijian:

(91) Fijian
a. по- $m u$
$i$-vaðu
GENP-2SG.PSSR NMLZ-punch
'your punch' (which you threw)
(Geraghty 1983: 248)
b. $\boldsymbol{k e}$ - $m u$
$i$-vaðu
FOOD-2SG.PSSR NMLZ-punch
'your punch' (which you received)
(Geraghty 1983: 248)

"Food"-marked passive possession also occurs with nominalized clauses in Standard Fijian, but here the distinction is solely one of animacy. The general host is used if the possessor is human, and the "food" host if the possessor is inanimate. Nominalized transitive clauses may be possessed by their human logical A using the general host, as in (92a). The logical O is possessor-indexed using the general host if human, but the "food" host if inanimate ([92b] and [92c]). Possessor-indexing of the logical $\mathrm{S}$ of a nominalized intransitive clause follows the same pattern ([92d] and [92e]).

(92) Fijian

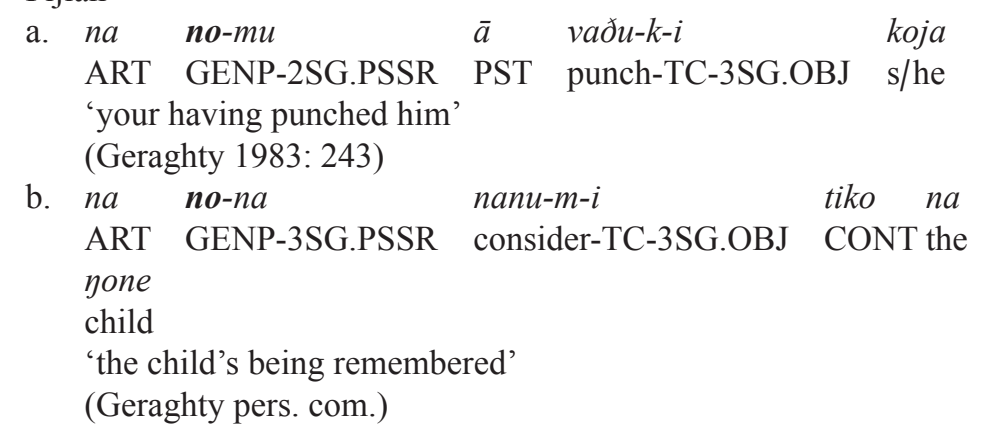




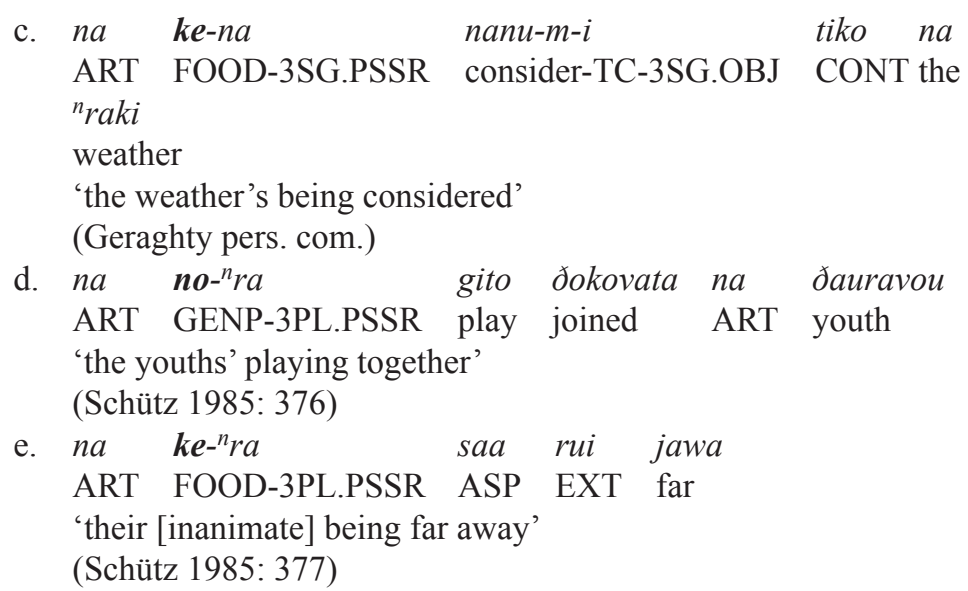

In a survey of 23 languages representing every first-order subgroup of Oceanic, Palmer (2007b) found that 15 of the 23 mark passive possession in some way, and of those, 11 mark passive possession using a host with the canonical function of marking items eaten. "Consumed"/"food" marking of passive possession occurs in every first-order subgroup of Oceanic in which passive possession is distinctively marked, and is therefore reconstructable for Proto Oceanic. Languages which employ another strategy (such as a dedicated passive possessive host or direct possessor-indexing) appear to have innovated these strategies, and those which lack distinct passive possessive marking have lost the category.

"Consumed" marking of passive possession of nouns has not been reported in NWS, although Mono displays an instrumental preposition that appears to have developed out of earlier 'consumed' indirect 3SG possessor-indexing of instruments used on a participant:

(93) Mono

koriomu ena ketau re-pipisi

Koriomu INSTR k.o.vine 3PL.SBJ.REAL-tie

'They tied up Koriomu with ketau-creeper.'

(Wheeler 1926: text 66)

However, passive possession of nouns is attested in two sister languages of NWS, Kuanua and Siar. In Kuanua, the "consumed" host "do[es] not express a relationship of control, but rather the relationship between an object and somebody or something that is affected by this object the possessor refers to somebody or something the referent of the possessed noun phrase is used on." (Mosel 1984: 38) This contrasts with the general host, which denotes an "active 
voluntary or controlling relationship" (Mosel 1984: 36). Passive possession applies to the possession of nouns:

(94) Kuanua

a. ra-na ram

CNSM-3SG.PSSR club

'its club' (it will be killed with)

(Mosel 1984: 38)

b. ka-dia rити

GENP-3SG.PSSR spear

'their spears' (they own)

(Mosel 1984: 38)

c. $m a \quad i \quad g a$ al $p a$ nam ra-na

and he T/A attract EFFECT DEM CNSM-3SG.PSSR

kankan

anger

'And he drew [their] anger upon himself.' (lit. '... $\mathrm{he}_{\mathrm{i}}$ attracted

his $\mathrm{s}_{\mathrm{i}}$ anger')

(Mosel 1984: 38)

In (94c) the possessor of the anger is not the ones who are angry, but the one to whom the anger is directed, and is indexed using the "consumed" host.

Possessor-indexed nominalized clauses are attested in Siar, as in (80a), and possessor-indexed nominalized verbs occur in Kuanua, as in (80b) and (95). The logical A of a nominalized transitive verb and the logical S of a nominalized intransitive verb are indirectly possessor-indexed using the general host, as (80b) and (95) show. However, this is confined to agentive As and the S of nominalized unergative verbs. The logical $\mathrm{S}$ of a nominalized unaccusative verb may not be possessor-indexed. "KA-possessors are used to indicate the agent of nominalized active verbs". (Mosel 1984: 35) The general, not "consumed", host is used because of "similarities between the semantic role of the agent of active verbs and that of the [general] possessor" (Mosel 1984: 36). The general host is therefore confined to dominant (i.e., nonpassive) possession, agreeing with a distinction between dominant possession using the general host and passive possession using the 'consumed' host.

(95) Kuanua
a. $r a$
$p<$ in $>$ ot
$<$ NMLZ>come
$\boldsymbol{k} a-i$ $r a$
umana katiket
ART $<$ NMLZ $>$ come GENP
'the arrival of the catechists'
(Mosel 1984: 35)
b. a $\quad k<u n>u \sim k u l$
ART $<$ NMLZ $>$ RD $\sim$ buy
$\begin{array}{lll}\boldsymbol{n} \boldsymbol{a} & k a r & \boldsymbol{k} \boldsymbol{a}-\boldsymbol{i} \\ \text { CONNECT } & \text { car } & \text { GENP-PSSR }\end{array}$




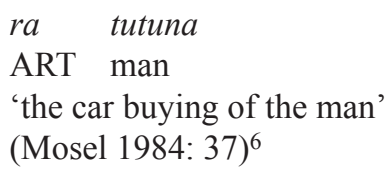

Although use of the 'consumed' host with the passive possession of nouns is unattested in NWS, the "consumed" host is attested with nominalized verbs in Nehan. The verbs with which it is attested are psych verbs, agreeing with the notion that the "consumed" host with nominalizations is confined to nonagentive possessors. Compare (96) with (87).

(96) Nehan

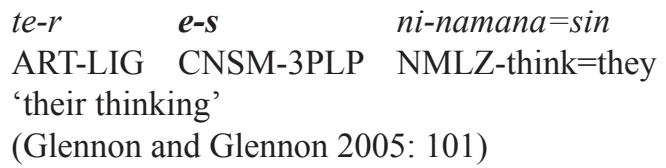

Unlike Standard Fijian, logical objects of nominalizations are directly possessor-indexed, not indirectly, and therefore could not employ a "consumed" host. The use of a "consumed" host to index a passively possessed nominalization could therefore only be expected with the logical S of a nominalized unaccusative intransitive verb. The existence of passive possession of nouns with a "consumed" host in Kuanua and Siar, the restriction on the possessor-indexing of nominalized verbs in Kuanua to the general host with an agentive logic S, and the presence of a "consumed" host indexing the logical S of unagentive nominalized psych verbs in Nehan together suggest that Proto South New Ireland/Northwest Solmonic, and PNWS itself, employed a "consumed" host to possessor-index passively possessed possessums, and applied this to nominalizations as well as underived nouns. This would accord with possessorindexed nominalizations as the source of the use of both former general and "consumed" hosts in synchronic PVSI.

The notion that passive possession marked with the "consumed" host accords with the functional distribution discussed in Section 5.2.12 and presented in Table 6 above. In languages where both the general and "consumed" hosts occur in PVSI, the "consumed" host occurs with events in which the subject is affected in some way, or over which the subject has no control, or is restricted to a particular kind of affect or lack of control.

\subsection{Possessed nominalized clauses in PNWS}

The evidence outlined above supports the following hypothesis:

(97) a. Synchronic PVSI developed out of a nominalized clause construction, not a nominalized verb. 


\section{B. Palmer}

b. The nominalized clause construction in PNWS allowed possessorindexing of its logical arguments. The logical A of a nominalized transitive clause and logical $\mathrm{S}$ of a nominalized unergative clause were possessor-indexed indirectly using the general indirect host; the logical S of a nominalized unaccusative clause was possessorindexed indirectly using the "consumed" host; and the logical O of a nominalized transitive clause was directly possessor-indexed.

c. Indirect possessor-indexing of nominalized clauses allowed right dislocation of the possessor-indexing host, probably on the basis of the weight of the possessum nominalization.

This article has presented a theory on the nature of the originating construction that gave rise to the use of possessive or former possessive morphology to index subjects in synchronic NWS, and how this development occurred. However, this in turn poses an unanswered question for future research - why the development took place. While the use of genitive case marking to mark subjects is well known, the development of nominal possessive morphology into subject agreement is extremely rare. The grammatical circumstances that prompted this development in this group of languages remain to be investigated.

Received 21 September 2004

University of Newcastle, Australia

Revised version received 16 August 2010

\section{Notes}

1. This research was supported by Arts and Humanities Research Council Research Grant APN19365 and British Academy Small Research Grant SG44063. This support is gratefully acknowledged. I am grateful to Greville Corbett, Dunstan Brown, Malcolm Ross, John Olstad, members of the Surrey Morphology Group, and two anonymous reviewers for comments on various versions of this article. I am indebted to Malcolm Ross for making his extensive primary notes on many NWS languages available to me, to Mary Chambers and Ian Scales for sharing unpublished materials on Kubokota and Duke, and Paul Geraghty for discussions on passive possession in Fijian. All errors remain mine. Correspondence address: School of Humanities and Social Science, University of Newcastle, Callaghan NSW 2308, Australia. E-mail: Bill.Palmer@newcastle.edu.au

2. Glossing abbreviations follow the Leipzig Glossing Rules with the following exceptions and additions: 1EXC 'first person exclusive'; 1INC 'first person inclusive'; 4 'fourth person'; AFFECT 'affected subject'; ASSOC 'associative', CNTRST 'contrastive marker'; CND 'conditional'; CNJ 'conjunction'; CONT 'continuous aspect'; CNSM “'consumed' possessive marker'; CS 'causativizer'; EFFECT 'effective particle'; EMPH 'emphatic marker'; FOOD 'possessive marker for items eaten'; GENP 'default possessive marker'; INTNS 'intensification of subject involvement', LIG 'ligature'; NT 'neutral modality'; PM 'predicate marker'; PSSM 'possessum'; PSSR 'possessor'; RD 'reduplicant'; REAL 'realis'; RSLT 'resultative continuous aspect'; SBD 'subordinator'; T/A 'tense/aspect'; TC 'thematic consonant'. 
3. Ross (1982) refers to the string of forms he investigates as the "verb phrase". However, he is concerned only with the verb and its accompanying argument-indexing, TAM and adverbial forms, and not the object NP, if any. This string is now usually referred to in the Oceanist literature as the "verb complex".

4. The New Georgia subgroup displays both direct and indirect indexing of logical S.

5. The host ke- is used for food only in Fijian. A separate host is used for drink.

6. In Kuanua, as in Siar (see Section 6.3.2), the possessor-indexing host is preposed to the possessum noun when no overt possessor NP is present, but postposed when a possessor NP does occur, as a comparison of (95a). and (80b). shows. Unlike Siar, the postposed host is not possessor-indexed, but is marked with a possessor marker $i$.

\section{References}

Allen, Jerry \& Conrad Hurd. 1963. Survey word list (Papapana). Unpublished manuscript.

Boch, Alois. n.d. Short Alu grammar. Unpublished manuscript.

Capell, Arthur. 1971. Austronesian languages of Australian New Guinea. In Thomas A. Sebeok (ed.), Linguistics in Oceania (Current Trends in Linguistics 8), 240-340. The Hague: Mouton.

Capell, Arthur. n.d. Petats field notes. Unpublished manuscript.

Carter, G. G. 1952. Some grammatical notes on the Teop dialect. Journal of the Polynesian Society 61(1/2). 230-242.

Chambers, Mary. 2009. Which way is up? Motion verbs and paths of motion in Kubokota, an Austronesian language of the Solomon Islands. London: University of London School of Oriental and African Studies doctoral dissertation.

Chambers, Mary. n.d. Kubokota field notes. Unpublished manuscript.

Comrie, Bernard. 1976. Aspect. Cambridge: Cambridge University Press.

Corston-Oliver, Simon. 2002. Roviana. In John Lynch, Malcolm D. Ross \& Terry Crowley (eds.), The Oceanic languages, 467-497. London: Curzon.

Davis, Karen. 2003. A grammar of the Hoava language, Western Solomons. Canberra: Pacific Linguistics.

Fast, Lesley. 1990. Tungak grammar essentials. In John R. Roberts (ed.), Two grammatical studies. 1-72. Ukarumpa: SIL.

Fitzsimons, Matthew. 1989. Zabana: A grammar of a Solomon Islands language. Auckland: University of Auckland MA thesis.

Geraghty, Paul. 1983. The history of the Fijian languages. Honolulu: University of Hawai'i Press.

Glennon, John \& Ariana Glennon. 1994. Nehan grammar essentials. Unpublished manuscript.

Glennon, John \& Ariana Glennon. 2005. Nehan dictionary. Unpublished manuscript.

Kettle, Eleanor. 2000. A description of the verb phrase in Ganoqa, an Austronesian language of the Solomon Islands. Canberra: Australian National University Honours thesis.

Laycock, Donald C. 1978. Ririo tape transcripts. Unpublished manuscript.

Lee, Yunseok. n.d. Transitivity in Petats. Unpublished manuscript. Australian National University.

Lichtenberk, František. 1985. Possessive constructions in Oceanic languages and Proto-Oceanic. In Andrew K. Pawley \& Lois Carrington (eds.), Austronesian linguistics at the 15th Pacific Science Congress, 93-140. Canberra: Pacific Linguistics.

Lincoln, Peter C. 1975. Sampela wot bilong tok Uruava. Unpublished manuscript.

Lincoln, Peter C. 1976. Describing Banoni, an Austronesian language of southeast Bougainville. Honolulu: University of Hawai'i Honolulu doctoral dissertation. 


\section{B. Palmer}

Lynch, John. 1996. Proto Oceanic Possessive-marking. In John Lynch \& Fa'afo Pat (eds.), Oceanic studies: Proceedings of the First International Conference on Oceanic Linguistics, 93-110. Canberra: Pacific Linguistics.

Lynch, John \& Malcolm D. Ross. 2002. Banoni. In John Lynch, Malcolm D. Ross \& Terry Crowley (eds.), The Oceanic languages, 440-455. London: Curzon.

Lynch, John, Malcolm D. Ross \& Terry Crowley (eds.). 2002. The Oceanic languages. London: Curzon.

Mosel, Ulrike. 1984. Tolai syntax and its historical development. Canberra: Pacific Linguistics.

Mosel, Ulrike \& Jessika Reinig. 2000. Valence changing clitics and incorporated prepositions in Teop (Oceanic, Bougainville, PNG). In Marian Klamer (ed.), Proceedings of AFLA7: The seventh meeting of the Austronesian Formal Linguistics Association, 133-140. Amsterdam: Vrije Universiteit Amsterdam Department of Linguistics.

Mosel, Ulrike \& Yvonne Thiesen. 2007. The Teop sketch grammar. Unpublished manuscript.

Oliver, Douglas. 1938. Uruava word list. Unpublished manuscript.

Palmer, Bill. 2002. Kokota. In John Lynch, Malcolm D. Ross \& Terry Crowley (eds.), The Oceanic languages. London: Curzon.

Palmer, Bill. 2007a. Imperfective aspect and the interplay of aspect, tense and modality in Torau. Oceanic Linguistics 46(2). 499-519.

Palmer, Bill. 2007b. Semantically non-canonical possessive marking and hierarchies of possession. Paper presented at the Association for Linguistic Typology 7 th biannual conference (ALT 7), Paris, 25-27 September.

Palmer, Bill. 2008. Passive possession in Oceanic. Studies in Philippine Languages and Cultures 18. 119-141.

Palmer, Bill. 2009. Kokota grammar. Honolulu: University of Hawai'i Press.

Palmer, Bill. n.d. Papapana and Zabana field notes. Unpublished manuscript.

Palmer, Bill \& Dunstan Brown. 2007. Heads in Oceanic indirect possession. Oceanic Linguistics 46(1). 199-209.

Rausch, Peter J. 1912. Die Sprache von Südost-Bougainville, Deutsche Salomonsinseln. Anthropos 7. 974-994.

Ross, Malcolm D. 1982. The development of the verb phrase in the Oceanic languages of the Bougainville region. In Amran Halim, Lois Carrington \& Stephen A. Wurm, Papers from the Third International Conference on Austronesian Linguistics, vol. 1: Currents in Oceanic, 1-57. Canberra: Pacific Linguistics.

Ross, Malcolm D. 1988. Proto Oceanic and the Austronesian languages of western Melanesia. Canberra: Pacific Linguistics.

Ross, Malcolm D. 2002a. Sisiqa. In John Lynch, Malcolm D. Ross \& Terry Crowley (eds.), The Oceanic languages, 456-466. London: Curzon.

Ross, Malcolm D. 2002b. Taiof. In John Lynch, Malcolm D. Ross \& Terry Crowley (eds.), The Oceanic languages, 426-439. London: Curzon.

Ross, Malcolm D. n.d. Babatana, Bannoni, Hakö, Nehan, Selau, Taiof and Tinputz field notes. Unpublished manuscript.

Rowe, Karen. 2005. Siar-Lak grammar essentials. Ukarumpa: SIL.

Ruffolo, Roberta. n.d. Verbal phrase in Petats. Unpublished manuscript, Australian National University.

Scales, Ian. n.d.a. Duke dictionary. Unpublished manuscript.

Scales, Ian. n.d.b. Duke field notes. Unpublished manuscript.

Schütz, Albert J. 1985. The Fijian language. Honolulu: University of Hawai'i Press.

Schwartz, Marcia L., Ruth Saovana Spriggs, Ulrike Mosel, Ruth Siimaa Rigamu, Jeremiah Vaabero \& Naphtaly Maion. 2007. The Teop Lexical Database. Kiel: Christian Albrechts Universität. <www.linguistik.uni-kiel.de/Teop_Lexical_Database_May07.pdf> 
Todd, Evelyn M. 1978. A sketch of Nissan (Nehan) grammar. In Stephen A. Wurm \& Lois Carrington (eds.), Second International Conference on Austronesian Linguistics: Proceedings, 1181-1239. Canberra: Pacific Linguistics.

Todd, Evelyn M. 2000. Roviana clauses. In Bill Palmer \& Paul Geraghty (eds.), SICOL Proceedings of the Second International Conference on Austronesian Linguistics, vol. 2: Historical and descriptive studies, 137-154. Canberra: Pacific Linguistics.

Waterhouse, J. H. L. 1949. A Roviana and English dictionary. Sydney: Epworth.

Wheeler, Gerald C. 1926. Mono-Alu folklore: Bougainville Strait, Western Solomon Islands. London: Routledge.

White, Geoffrey M., Francis Kokhonigita \& Hugo Pulomana. 1988. Cheke Holo (Maringe/ Hograno) dictionary. Canberra: Pacific Linguistics. 